\title{
First Language
}

http://fla.sagepub.com

\section{Learning to talk and gesture about motion in French}

Marianne Gullberg, Henriëtte Hendriks and Maya Hickmann

First Language 2008; 28; 200

DOI: $10.1177 / 0142723707088074$

The online version of this article can be found at:

http://fla.sagepub.com/cgi/content/abstract/28/2/200

\author{
Published by: \\ (5)SAGE Publications \\ http://www.sagepublications.com
}

Additional services and information for First Language can be found at:

Email Alerts: http://fla.sagepub.com/cgi/alerts

Subscriptions: http://fla.sagepub.com/subscriptions

Reprints: http://www.sagepub.com/journalsReprints.nav

Permissions: http://www.sagepub.com/journalsPermissions.nav

Citations (this article cites 28 articles hosted on the

SAGE Journals Online and HighWire Press platforms):

http://fla.sagepub.com/cgi/content/refs/28/2/200 


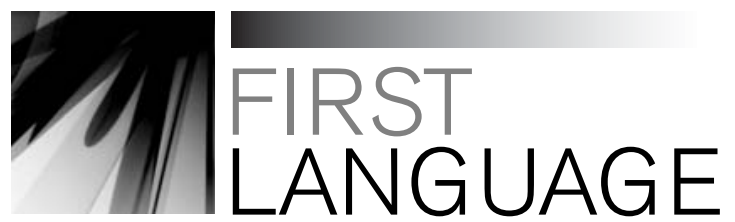

Copyright (C) 2008 SAGE Publications (Los Angeles, London, New Delhi, and Singapore) www.sagepublications.com Vol 28(2): 200-236 (200805)

\title{
Learning to talk and gesture about motion in French
}

Marianne Gullberg, Max Planck Institute for Psycholinguistics, Nijmegen

Henriëtte Hendriks, Cambridge University

Maya Hickmann, Centre National de la Recherche Scientifique \& Université de Paris 8

\begin{abstract}
This study explores how French adults and children aged four and six years talk and gesture about voluntary motion, examining (1) how they encode path and manner in speech, (2) how they encode this information in accompanying gestures; and (3) whether gestures are co-expressive with speech or express other information. When path and manner are equally relevant, children's and adults' speech and gestures both focus on path, rather than on manner. Moreover, gestures are predominantly co-expressive with speech at all ages. However, when they are non-redundant, adults tend to gesture about path while talking about manner, whereas children gesture about both path and manner while talking about path. The discussion highlights implications for our understanding of speakers' representations and their development.
\end{abstract}

\section{KEYWORDS}

French; gestures; language development; manner; path; representation of motion 


\section{INTRODUCTION}

Crosslinguistically, languages display considerable variation with respect to their semantics, a fact which has raised some questions concerning universal vs. languagespecific determinants of language use and language acquisition. The spatial domain has been particularly well studied in this respect, showing that languages vary a great deal in how they encode information concerning, for instance, motion events (see, e.g., papers in Aurnague, Hickmann \& Vieu, 2007; Levinson \& Wilkins, 2006; Strömqvist \& Verhoeven, 2004). Speakers of different languages appear to target and select different types of spatial information related to motion for expression - a process alternatively referred to as linguistic conceptualization, event construal or perspective taking - and to encode this information in diverse lexical and morphosyntactic ways. Moreover, such linguistic variability has been shown to play a role during language development, influencing the timing and course of children's acquisition of various spatial expressive means (e.g., Bowerman, 1996; Bowerman \& Choi, 2003; Slobin, 1996; 2003).

In much research concerned with questions of linguistic conceptualization, it remains a vexing issue what types of spatial information speakers really consider as relevant when they talk about motion. It is also not clear whether differences in spoken language alone are informative in this regard. For instance, one cannot automatically conclude that the absence of an overt mention of, say, manner of motion means that the speaker has not attended to this information. This issue is equally problematic for studies concerned with crosslinguistic and developmental differences. Interestingly, recent studies focusing on all available means for expressing meaning - speech as well as gestures - have shown systematic cross-linguistic differences in how adult speakers gesture as they talk about space (Duncan, 1996; Kita \& Özyürek, 2003; McNeill, 1992, 2005; Özyürek, Kita, Allen, Furman \& Brown, 2005). This body of work suggests that speech and gesture form a tightly integrated system in which both modalities reflect important aspects of the meaning selected for expression. With speech and gestures both providing information about meaning, gestures can shed light on crosslinguistic differences in meaning representations and linguistic conceptualization. Specifically, gestures can potentially reveal more about what types of spatial information speakers consider for expression as discourse unfolds than speech alone can. Analyses of speech and gesture in combination in turn open up new possibilities for examining how language-specific representations develop in childhood, allowing us to examine whether children consider the same spatial information when speaking as adults do, and whether the relationship between speech and gestures changes during development.

The present paper focuses on the relationship between speech and gestures during the expression of motion events. Despite some available studies in this domain, surprisingly little is known about the development of language-specific expressions of motion in speech and gesture crosslinguistically. In this context, the present study explores how French adults and children (aged four and six years) talk and gesture about voluntary motion, and particularly: (1) how they encode information about path and manner in speech, with particular attention to whether 
children are attuned to typological factors that constrain the adult system; (2) how they encode information about path and manner in speech-associated gestures; and (3) the extent to which accompanying gestures are co-expressive with speech or may be recruited to express information not encoded in speech, in particular in children.

\section{Motion in spoken French}

French provides several ways of expressing motion events. If we focus on voluntary motion spontaneously carried out by an agent, two main patterns emerge with respect to the expression of path and manner. First, utterances such as example (1) contain a main verb lexicalizing manner. Such utterances are typically used if the speaker's focus is on manner, for instance, when motion takes place within a general location (i.e., she is in the kitchen and walking within it). However, if motion involves a change of location, a second utterance structure is typically used. In this case, as shown in (2), French predominantly encodes path in the verb, whereas manner is rarely expressed (but see below). Notwithstanding other satellite-framing properties of the French spatial system (Kopecka, 2006), such a pattern is characteristic of what Talmy (2000) has called verb-framed languages. In contrast, languages such as English show a strong preference for satellite-framing. In this case, as shown in (3), main verbs lexicalize manner, even when motion involves location changes, while verbal satellites compactly express path together with manner in cases of location changes.

(1) Elle marche, court, saute, nage, vole, rampe ... dans la cuisine. 'She's walking, running, jumping, swimming, flying, crawling ... in the kitchen.'

(2) Elle monte, descend, entre dans, sort de, part de, traverse ... la cuisine. Lit. 'She ascends, descends, enters in[to], leaves from, crosses ... the kitchen.'

(3) She runs up, down, into, out of, away from, across ... the kitchen.

The patterns above correspond to paradigms that capture strong preferences on the part of speakers, but they are not by any means the only available ways of expressing motion. Exceptions to the predominant pattern occur in verb semantics, for example Latinate verbs in English (e.g., to ascend, to exit) and verbs that lexicalize manner and path in French, e.g., grimper 'to climb up', which represents motion as simultaneously involving a particular path (necessarily upwards) and a certain manner (with limbs and with some effort). ${ }^{1}$ Examples such as (4) and (5) also show cases where French speakers can use various devices to express path information in the periphery of a manner verb or manner information in the periphery of a path verb. However, such utterances are typically rather marked in the sense that the speaker emphasizes some particular aspect of the event (e.g., an unusual manner of motion and/or the fact that the person covered an entire distance to reach his destination). They frequently also require more complex constructions than in satellite-framed languages (e.g., subordinate clauses). 
(4) Il a couru à l'école. / Il est allé jusqu'à l'école sur un pied.

'He ran to school.' / 'He went all the way to school on one foot.'

(5) Il a traversé la route en courant. / II a traversé à quatre pattes.

'He crossed the road running.' / 'He crossed the road on all fours.'

A number of crosslinguistic studies examine the implications of this typology for language acquisition (e.g., Allen, Özyürek, Brown, Furman \& Ishizuka, 2003; Allen et al., 2007; Berman \& Slobin, 1994; Bowerman, 1996, 2007, Bowerman \& Choi, 2001, 2003; Choi \& Bowerman, 1991; Hickmann, 2003; Slobin, 1996, 2004, 2006). For example, analyses based on narratives (Berman \& Slobin, 1994; Slobin, 2004) show that speakers of satellite-framed languages generally talk more about motion, that they do so in more elaborate ways, and that they pay more attention to manner in comparison with speakers of verb-framed languages. Furthermore, results indicate that typological constraints affect children's speech from the youngest age on, in relation to both voluntary and caused motion, and during early phases of production (Choi \& Bowerman, 1991) and of comprehension (Bowerman \& Choi, 2001).

On the basis of these striking crosslinguistic differences, some authors have claimed (Bowerman and Slobin and collaborators) that children may follow different strategies during first language acquisition as a function of the lexicalization patterns with which they are confronted and particularly the degree to which verbs lexicalize manner or path. Furthermore, these authors have hypothesized that language particulars may influence speakers' linguistic conceptualization. According to this view, language systems make some aspects of incoming information more salient and therefore more accessible, thereby inviting speakers to pay more attention to them. However, such claims run the risk of circularity as long as only speech is examined. In this respect, speech-associated gestures can provide further information on what spatial information is taken into account as adult and child speakers construct their conceptual representations during speech.

In this context, although much is known about the spatial system of French (Aurnague, 1995, 1996; Borillo, 1998; Vandeloise, 1991), very little research has focused on this domain in French child language. Most available studies have examined the acquisition of spatial prepositions in static situations (Piérart, 1978; Verjat, 1991). More recent research examines how French speakers talk about both voluntary and caused motion in French vs. English (and other satellite-framed languages). The data include early spontaneous productions from children aged 2-4 years (Hickmann, Hendriks \& Champaud, 2008) and productions elicited in experimental situations from children aged 3 years and onward and from adults (Hickmann, 2003, 2006, 2007; Hickmann \& Hendriks, 2006; Hickmann, Taranne \& Bonnet, submitted). With respect to voluntary motion, French speakers' utterances contain dynamic predicates that are less varied and less semantically dense in comparison with those produced by English speakers. Young French children tend to focus on one type of information at a time (either path or manner) and/or to produce multisentence responses in which they string together different pieces of information about locations, path and manner in discourse (II arrive au bord de la rivière, il plonge, il nage et il va jusqu'à l'autre côté 'He arrives at the river bank, he dives, he 
swims and he goes to the other side'). In contrast, English children of the same ages produce significantly more utterances conflating manner and path, although there are developmental changes also to this pattern. Semantic density also increases with age in French such that French adults jointly encode path and manner more frequently than children do, although they still do so less frequently than English adults.

\section{Gestures and the expression of motion}

A steadily growing body of research suggests that speech-associated gestures, ${ }^{2}$ defined as symbolic movements related to the speaker's expressive intention, form an integrated system with speech (Clark, 1996; Kendon, 2004; McNeill, 1985, 1992, 2005). The two modalities are semantically, temporally and pragmatically coordinated. The most meaningful part of a gesture, the stroke, is typically temporally coordinated with a co-expressive part of speech (Kendon, 1980; McNeill, 1992). Following McNeill $(1985,1992,2005)$, a number of scholars now argue that this coordination is indicative of shared representations between the modalities, specifically at the conceptual level (e.g., De Ruiter, 2000, 2007; Kita \& Özyürek, 2003). A specific proposal, the so-called Interface Hypothesis, states that imagistic information about a given event and the linguistic encoding of the same event interact at the conceptual level such that both information sources contribute to shape gestures (Kita \& Özyürek, 2003). Shared conceptual representations between speech and gesture in turn mean that gestures could reflect the ongoing processes of linguistic conceptualization as speakers construe discourse online, that is to say, what (spatial) information they take into account as they speak. This claim is supported by observations of systematic differences in adult gestural patterns across languages reflecting differences in what information is selected for expression as well as the way in which this information is subsequently encoded in speech. Specifically, typological differences between satellite- and verb-framed languages in how elements like path and manner are mapped onto different morphosyntactic structures is reflected in crosslinguistically different adult gesture practices (Brown, 2007; Brown \& Gullberg, 2008; Duncan, 1996; Kita \& Özyürek, 2003; McNeill, 1992; McNeill \& Duncan, 2000; Özyürek et al., 2005). Speakers of satellite-framed languages like English tend to encode manner and path in one spoken clause and to perform one gesture that encodes both elements conflated in one single movement. In contrast, speakers of verb-framed languages like Turkish who want to express both path and manner tend to use two clauses, one finite verb expressing the path, and optionally another verb expressing the manner of motion. They are also more likely to perform two accompanying gestures, each expressing path and manner separately (Kita \& Özyürek, 2003, 2007; Özyürek et al., 2005). The specific view that the syntactic mapping of meaning is reflected in gesture - a one-clauseone-gesture vs. a looser two-clauses-two-gestures pattern - is further supported by the observation of within-language variation in gestures depending on what structures speakers actually use (Özyürek et al., 2005).

A further implication of these findings is that gestures generally co-occur with speech expressing similar content. That is, gestures expressing path, manner or path 
and manner together tend to accompany speech expressing path, manner or path and manner together. In other words, speech and gesture tend to be co-expressive. However, a complication arises for verb-framed languages and the expression of manner. It has been suggested that because manner is not always overtly expressed in speech in verb-framed languages - either because of the smaller manner verb lexicons, or because of the structural complexities of subordinate structures, or both - speakers may chose to express manner in gesture even if it is absent in speech (McNeill, 2000). For instance, speakers of Spanish, a verb-framed language, may gesture about manner even though there is no obvious corresponding manner expression in speech (Duncan, 2005; McNeill, 2000; McNeill \& Duncan, 2000). Moreover, because these manner gestures have no equivalent spoken manner expression with which to align, they may spread out over the clause in 'fogs' (McNeill, 2000; McNeill \& Duncan, 2000), or align with seemingly unrelated elements such as nominal ground expressions (Duncan, 2005). The Spanish findings suggest that gestures may be recruited as a mode of expression for manner in a compensatory fashion, and/or as a reflection of a different, more holistic representation of motion. In both cases, spatial information not expressed in speech would nevertheless be part of the conceptualization of motion. Because the linguistic encoding options for manner in verb-framed languages are less readily available or structurally more complex, it is empirically possible that speakers of verb-framed languages in general are less co-expressive in speech and gesture than speakers of satellite-framed ones.

Turning to children, gestures and speech have been shown to develop in parallel in childhood (Capirci, Contaldo, Caselli \& Volterra, 2005; Capirci, Iverson, Pizzuto \& Volterra, 1996; Guidetti, 2005; Jancovic, Devoe \& Wiener, 1975; Mayberry \& Nicoladis, 2000; Volterra, Caselli, Capirci \& Pizzuto, 2005). Although speech and gestures generally display tightly coupled and parallel development, a number of studies show that children's speech and gestures are not always entirely co-expressive. Gestures may 'foreshadow' speech in development such that children first express meaning in gesture before it is deployed in speech, and before they go on to use both modalities in parallel (Alibali \& Goldin-Meadow, 1993; Capirci et al., 2005; Church \& Goldin-Meadow, 1986; Goldin-Meadow, 2003; Guidetti, 2002, 2005; Pine, Lufkin \& Messer, 2004). Children's use of gesture to express nonredundant meaning to speech (so called 'mismatches') or meaning not accessible to the spoken system, has been seen as an indication of cognitive development or 'transitional knowledge states'. Such cases seem to predict imminent transition from the one- to the two-word stage (Capirci et al., 1996; Goldin-Meadow \& Butcher, 2003), as well as continuing development in later childhood (Özçalışkan \& GoldinMeadow, 2005).

Despite the general interest in children's gestures, very little is known about how children express event information in speech and gesture and how the modalities interact in development to reflect language-specific event representations. McNeill (2005) has suggested specific developmental changes in how meanings related to voluntary motion are distributed across modalities. He has proposed that very young English-, Mandarin- and Spanish-speaking children go from an early holistic stage where they gesturally display what he calls the 'full complexity' of a motion 
event, i.e., both path and manner as perceived, to a stage around age 3-4 years where they gesturally decompose the event into either pure path or pure manner, and rarely conflate the two. He suggests that this decomposition in gesture is like children's well-known desire to map one meaning onto one form in speech (e.g., Bowerman, 1982). Similar transitions from a holistic to an analytic encoding of motion are attested in the diachronic development of Nicaraguan Sign Language (Senghas, Kita \& Özyürek, 2004).

McNeill further proposes that English-, Mandarin- and Spanish-speaking children tend to express manner and path in different viewpoints regardless of the typological preferences of the adult speakers of these languages. Specifically, he argues that children express manner in character-viewpoint, i.e., that they map the protagonist's body parts onto their own bodies and enact an event. He further suggests that children express path in observer-viewpoint, i.e., that their hands typically represent the protagonist as a whole as observed from the outside. The two observations taken together suggest a possible developmental trend for verb-framed languages whereby younger children, who are more likely to represent the perceptual properties of events as they happened through enactment or character-viewpoint, are also likely to express more manner than older children. Older children, in contrast, who express events mainly from an observer-viewpoint, may show language-specific preferences for expressions of path and manner.

The various aspects just reviewed all raise questions about what similarities and differences might be found in the conceptualization of motion across languages and developmental stages. French, a verb-framed language like Turkish and Japanese, but with some satellite-framed components (Kopecka, 2006), could considerably further our understanding of these issues. However, to date very little is known about the multimodal expression of motion in French both in adult usage and in development. One study examining the expression of motion in FrenchEnglish bilingual children aged 3;6-4;11 found that speech in both languages was dominated by expressions of path, and that the iconic gestures in both languages mainly encoded path (Nicoladis \& Brisard, 2002). Moreover, the modalities encoded similar information, that is, the absence of manner or manner conflated with path in gesture was reflected by their absence in speech. Although suggestive, this study targeted bilingual children but provided no adult (bilingual) data for comparison. Further, the analysis comprised a total of 25 target gestures, only 7 of which pertained to French. It therefore remains an open question what speech-gesture patterns monolingual French adults and children display as they talk about motion, and how they encode and distribute information about path and manner across the modalities.

\section{The present study}

The aim of the present study is to examine how French adults and children gesture about motion while speaking, thereby providing hitherto unavailable data concerning the multimodal expression of motion in French. Our ultimate goal is to further our understanding of how linguistic conceptualization functions and develops. As a first step towards this end, we examine spoken and gestural representations of 
motion with particular attention to the expression of path and manner for different types of motion events: crossing events and upward/downward motion. These events are among the most familiar to young children and experimentally easy to manipulate, while presenting striking typological contrasts across languages. For all event types we examine both the spoken and gestural behavior of monolingual French children (aged 4 and 6 years) in comparison with that of adults to determine the extent to which (1) they are attuned to the language-specific ways of talking and gesturing about path and manner, and (2) their speech and gestures are coexpressive.

With respect to speech, previous results based on a similar experimental procedure (Hickmann, 2006; Hickmann, Taranne \& Bonnet, submitted) showed that French speakers focused their speech much more on the path of motion (traverser 'to cross', monter/descendre 'to ascend/descend') than on manner. This pattern was expected, given the properties of French. It was observed at all ages (children aged 3-7 years and adults), despite an increasing use of utterances jointly expressing manner and path with age. This developmental progression (particularly striking in French as compared with English) results from the greater complexity of such utterances (e.g., subordinated clauses as in traverser en courant 'to cross by running') in comparison with those expressing each component separately.

However, the results also showed differences in children's descriptions as a function of event types. In particular, although young French children showed an overall tendency to focus on path alone, they also produced two other response types: (a) when describing upward motion, they sometimes used a verb that lexicalized manner + path information (grimper 'to climb up'; see Note 1), thereby producing semantically dense but structurally simple utterances; (b) when describing boundary crossing, they rarely used the path verb traverser ('to cross', frequently used by French adults), either using the ambiguous path verb passer ('to pass', which need not mark boundary crossing) or focusing on manner alone. ${ }^{3}$ In addition, downward motion elicited less manner information than other events. This last finding also held for English, despite the fact that path + manner responses were significantly more frequent in English than in French, regardless of age and of event type.

Several factors jointly account for these findings. First, as predicted, gravity is most salient to children, inviting them to pay more attention to path in the case of upward/downward motion (vertical axis) as compared with crossing events (horizontal axis). Second, French children conflated manner and path more frequently and earlier with upward motion, because they used a common verb lexicalizing both types of information (available in French for upward motion but not for downwards or crossing events). Finally, the lower frequency of manner + path responses in both languages when vertical motion was directed downward rather than upward resulted from subjects' increasing reliance on discourse with age: if they had mentioned manner + path for a given upward event, participants (children older than 5 years and especially adults) sometimes presupposed manner for the immediately subsequent downward event. Thus, depending on age, and notwithstanding the fact that manner was overall more frequent in English at all ages, event types were roughly ordered as follows in both languages with respect to the simultaneous expression of manner + path: up $\geqslant$ down $>$ across for children, 
up $=$ across $>$ down for adults. Similar findings were expected with respect to speech in the present study.

Based on these results and previous findings for adult gesture production in verbframed languages, the following predictions were made with respect to speechassociated iconic gestures.

French adults:

(a) French adults will produce more path gestures than manner gestures, reflecting their typologically and lexically conditioned attention to path over manner.

(b) French adults will favour separate expressions of path and manner over conflated ones.

(c) French adults will align their path and manner gestures with speech about path and manner, respectively, and consequently be co-expressive in speech and gestures.

French children:

(d) French children aged 4 and 6 years will be attuned to the adult patterns and therefore overall will produce more path gestures than manner gestures.

(e) French children will favour separate expressions of path and manner over conflated ones.

(f) Although generally attuned to the language-specific patterns, children may nevertheless be guided by the perceptual properties of events as they describe them (McNeill, 2005), and may therefore recruit gestures to express information not encoded in speech. Children may therefore be less co-expressive overall and display more cases of non-redundant meaning in speech and gestures than adults. If so, this tendency may be subject to change developmentally, showing more cases of non-redundant meaning in the youngest children.

(g) Given the structural difficulties in expressing manner together with path in French, non-redundant meaning in French children's gestures may be mainly manner-oriented and expressed in character-viewpoint (McNeill, 2005), with possible exceptions when their speech is not path-oriented.

\section{METHOD}

\section{Participants}

The data presented here constitute a small subset of a larger database comprising several tasks, age groups and languages. From this database we extracted the speech and gestures produced by 18 speakers, both males and females, during one particular task involving the description of voluntary motion events. Six speakers each were selected from three age groups: six 4-year-olds (mean age 4;3, range 
$3 ; 11-4 ; 7)$, six 6 -year-olds (mean age $6 ; 4$, range $5 ; 10-6 ; 8$ ), and six adults (20-30 years). Children were enrolled in schools at Vanves (suburb of Paris). The 4-year-olds were in their second year of pre-elementary school (École maternelle, moyenne section), the 6-year-olds in their first year of primary school. Adults were students enrolled at the University of Paris 5.

\section{Materials}

The materials consisted of short animated cartoons in colour (of a few seconds each) presented on a computer screen manipulated by the experimenter. Each cartoon showed a human or animal character moving in a particular manner (e.g., running, swimming). In total there were 24 cartoons, corresponding to two series (see Appendix). In the 'main' series (12 items) characters performed one of several types of motion events against a background scenery (e.g., a forest): in half of them (6 items) they crossed boundaries (e.g., a river), and in the other half (6 items) they moved up and down a vertical axis (e.g., a tree). In all cartoons the character first appeared on the scene, performed the target motion event(s) and other actions (e.g., getting food, eating it), then left the scene. The 'control' series (12 items) was constructed in such a way as to render manner information maximally salient and path information minimally relevant. The background scenery was removed and the motion carried out by the character when entering/leaving the scene in the main series was shown continuously from one side of the blank screen to the other (from left to right or in the reverse direction). ${ }^{4}$ The rationale for control items was twofold. First, main vs. control items provided the possibility of making contrasting predictions. Since manner was the main relevant semantic component in the control items, subjects were expected to focus on this information (manner verbs). In contrast, with main items, where manner and path were equally relevant, subjects were expected to focus on path, given the properties of French (path lexicalized in verbs). Second, control items were also meant to ascertain that children were able to produce manner verbs spontaneously if they had not done so with the main items.

\section{Procedure}

Participants were tested individually in their school or university. In order to ensure complete descriptions, the experimenter asked them to describe to a naive listener what had happened in each cartoon. Young children (pre-primary school) were introduced to a doll, which was then blindfolded, and they were asked to tell her their 'secret' because she could not see. Primary school children and adults were simply asked to address a future interlocutor who could not see the cartoons and who would have to reconstruct them on the basis of the recordings.

Each participant saw all items, first those in the main series, then those in the control series. ${ }^{5}$ The items in each series were presented in six random orders, which differed from participant to participant. Each series (main and control) started with a training item that illustrated the types of items that would be shown and ensured that children felt comfortable with the task. The participant therefore saw a total of 26 items: a training item introducing the main series, 12 main items, a training item 


\section{VOLUME 28 ISSUE 2}

introducing the control series, and finally 12 control items. During the first training item, the experimenter announced that she would show the first cartoon and asked questions if participants' responses were insufficient (e.g., mere labelling with young children). The experimenter then maintained phatic contact but avoided intervening subsequently, unless children provided insufficient information (static or off-task information) or showed some difficulties in understanding what had happened (e.g., the experimenter might ask 'Yes and what happened?').

Participants were seated in front of the computer screen and side-by-side with the experimenter. The set-up nevertheless ensured a communicative setting conducive to gesturing. The participants were not aware that gestures were of interest to the study. The entire session was audio- and video-recorded, and recordings were then digitized.

\section{Coding of speech}

Responses were typically more elaborate with main items (6) than with control items (7). In the former case, they frequently included more than target events (TAR in bold), such as scene setting, initial states and/or entries at the beginning (BEG), resulting states and/or exits at the end (END), as well as other events that were irrelevant to the analyses below (IRR).

(6) Là on a une souris qui apparaît à droite de l'écran [BEG], qui arrive à un pied de table $[\mathrm{BEG}]$, monte sur le pied de table jusqu'à un morceau de fromage [TAR-up], prend le morceau de fromage [IRR], descend... redescend la table par le pied de table en se laissant glisser [TARdown] et ... s'en va vers la droite et disparaît à droite de l'écran [END], donc emportant le morceau de fromage [END]. $\quad$ (AD15, XSOU) ${ }^{6}$ 'There we have a mouse that appears on the right of the screen, that arrives at a table leg, ascends on the table leg to a piece of cheese, takes the piece of cheese, descends ... descends again the table by the table leg by sliding and leaves towards the right and disappears on the right of the screen, thus taking the piece of cheese away.'

(7) C'est une souris qui marche sur la pointe des pieds [TAR-control].

(0621, CSOU)

'It's a mouse that is tiptoeing' [Lit. 'walking on the tip of the feet']

Responses were segmented into propositions, each coded with respect to expressed manner and path information. As illustrated in (8)-(10), target descriptions fell into five types: only path $(P)$, only manner $(M)$, both $(P M)$, neither $(Z)$, no response. The Z-category included responses in which neither path nor manner was explicitly mentioned (e.g., expressions such as faire comme ça 'to do like that') or only neutral motion verbs were used (e.g., aller 'to go'). Occasional cases coded as 'No response' were either 'off task' (e.g., jouer 'to play') or did not include any mention of a 
target event at all (e.g., upward motion expressed, but downward motion entirely presupposed).

(8) ... il a grimpé au bananier [TAR-PM], a pris une banane [IRR], est redescendu [TAR-P] et puis est reparti du côté gauche [END].

(AD22, XSIN)

'he climbed up the banana tree, took a banana, descended and then left on the left side.'

(9) C'est quelqu'un qui court [BEG], qui est sur la neige [BEG] et après il glisse sur la glace [TAR-M] et après il retourne vers sa maison [END].

(0621, XGLI)

'It's someone who is running, who is on the snow and then he slides on the ice and then he goes back towards his house.'

(10) Elle a fait comme ça [TAR-Z], après elle est partie par là [END].

(0422, XPAT)

'... She did like that, then she left this way.'

For each denoted target event, most responses consisted of a single sentence (which could contain one or more clauses). Remaining responses contained more than one relevant sentence for a given event (hereafter multi-sentence responses), only one of which was selected for the purposes of statistical analysis. ${ }^{7}$ Table 1 shows the overall distribution of single sentences (overall 79\%), multiple sentences (18\%) or no response (3\%).

Among all produced responses, the vast majority (92\% at 4 years, $85 \%$ at 6 years, $71 \%$ at adult age) consisted of straightforward single-sentence responses. Three major types of multiple-sentence responses occurred. Some (overall 2\%) provided information that was entirely redundant in discourse, i.e., two P-responses or two M-responses were equivalent for the purposes of the analyses below, e.g., (11) in which the second P-proposition is a sort of 'afterthought', equivalent to the first. When multiple propositions did not provide equivalent information, two criteria were used for target response selection. In some cases (overall 9\%) one utterance was 'richer' than others (i.e., [PM] vs. [P] or [M], as in (12) and (13)) and it was therefore systematically selected as the target response, since it showed high semantic density (predicted not to occur). Other responses (overall 5\%) contained two or more relevant $\mathrm{M}$ - and $\mathrm{P}$-sentences, but $\mathrm{M}$-sentences ambiguously referred either to the target event or to some other event, while P-sentences unambiguously referred to the target (and were therefore selected). In example (14) (crossing item in which a baby crawled throughout), path unambiguously corresponds to crossing (TAR-P), but manner is relevant either to arrival or to crossing (BEG/TAR-M). The application of these coding criteria was entirely straightforward and resulted in high interrater reliability between two coders (98\%). The few remaining cases $(2 \%)$ were coded on the basis of what the two coders agreed seemed to be the most relevant and unambiguous target utterance. 
Table 1 Distribution of verbal responses consisting of single sentences, multisentences, or no response per age group in the main $(X)$ and control (C) series

\begin{tabular}{lcccc}
\hline & 4 years & 6 years & Adults & Total \\
\hline Main items $(X)$ & & & & \\
Single-sentence & $88(81 \%)$ & $87(81 \%)$ & $76(70 \%)$ & $251(77 \%)$ \\
Multi-sentence & $13(12 \%)$ & $19(18 \%)$ & $32(30 \%)$ & $64(20 \%)$ \\
No response & $7(6 \%)$ & $2(2 \%)$ & 0 & $9(3 \%)$ \\
Total & 108 & 108 & 108 & 324 \\
Control items $(C)$ & & & & \\
Single-sentence & $65(90 \%)$ & $61(85 \%)$ & $49(68 \%)$ & $175(81 \%)$ \\
Multi-sentence & $3(4 \%)$ & $9(13 \%)$ & $23(32 \%)$ & $35(16 \%)$ \\
No response & $4(6 \%)$ & $2(3 \%)$ & 0 & $6(3 \%)$ \\
Total & 72 & 72 & 72 & 216 \\
\hline
\end{tabular}

(11) ... et il traverse cette route à quatre pattes, il traverse tout le carrefour à quatre pattes. (AD14, XBEB) 'and he is crossing this road on all fours, he is crossing the whole intersection on all fours.'

(12) ... Arrivée en bas de cette branche, elle l'escalade toujours en se faisant glisser grâce à ses petites ventouses [TAR-PM], elle monte jusqu'en haut [TAR-P], se dirige vers la feuille [TAR-P] ... '...[Once it had] arrived at the bottom of this branch, it climbs up still letting itself slide by means of its little suckers, it ascends to the top, goes towards the leaf ...'

(13) ... Il a nagé [TAR-M], il a traversé en nageant [TAR-PM] ...

(0603, XNAG) '... He swam, he crossed by swimming ...'

(14) ... on voit ce bébé qui marche à quatre pattes [BEG/TAR-M], qui part du pâté de maisons gauche $[\mathrm{BEG}]$... et donc il marche à quatre pattes [BEG/TAR-M], il traverse la route [TAR-P] et il arrive au pâté de maisons droit et il sort de l'écran [END].

(AD09, XBEB) 'one sees a baby that is walking on all fours, that leaves from the left block of houses ... and so he walks on all fours, he crosses the road and he arrives at the right block of houses and he goes out of the screen.' 


\section{Coding of gestures}

All iconic or representational gestures related to the expression of motion that occurred within the spoken target descriptions were identified using frame-byframe analysis of digital video in video annotation software (Mediatagger; Brugman \& Kita, 1995). Two types of gestural phases were considered: (a) gestural strokes, i.e., the meaningful part of the gestural movement where the spatial excursion of the limb reaches its apex, and (b) post-stroke holds, or cases where the hands are temporarily immobile in gesture space before they move on (Kendon, 1980, 2004; Kita, Van Gijn \& Van der Hulst, 1998; Seyfeddinipur, 2006).

In the same software, we also noted the speech that co-occurred exactly with the stroke. Strokes do not neatly align with whole words but can cover multiple words as well as parts of words or single syllables. If a stroke covered a full syllable of a word, then that word was judged to co-occur with the stroke. If the stroke covered only a syllable-initial or syllable-final consonant but no vowel, then it was not deemed to co-occur with the word. In (15) the stroke is judged to co-occur with après 'after' since it covers the whole syllable près, and similarly to co-occur with glisser 'slide' since it covers the syllable glis. In contrast, in (16), the gesture is not deemed to co-occur with the verb grimper 'climb up' since it does not cover any syllabified part of the word, but only the consonant cluster gr.

(15) (a)près elle s'est laissée glis(ser)

(0610, XCHE)

(16) eh gr(impe)

(AD07, XCHE)

Table 2 summarizes the total number of iconic gestures per individual and age group in the main and control series.

Table 2 Number of gestures per participant and age group in the main (X) and control (C) series

\begin{tabular}{|c|c|c|c|c|c|c|c|c|}
\hline \multicolumn{3}{|c|}{4 years } & \multicolumn{3}{|c|}{6 years } & \multicolumn{3}{|c|}{ Adults } \\
\hline Code* & $x$ & $C$ & Code* & $x$ & $C$ & Code* & $x$ & $C$ \\
\hline 0404 & 14 & 3 & 0603 & 8 & 2 & AD07 & 17 & 8 \\
\hline 0407 & 14 & 1 & 0605 & 24 & 7 & AD09 & 19 & 2 \\
\hline 0412 & 9 & 1 & 0610 & 22 & 16 & AD14 & 7 & 1 \\
\hline 0414 & 7 & 1 & 0613 & 2 & 4 & AD15 & 3 & - \\
\hline 0417 & 15 & 3 & 0618 & 15 & - & AD20 & 5 & - \\
\hline 0422 & 20 & 6 & 0621 & 8 & - & AD22 & 17 & - \\
\hline Total & 79 & 15 & & 79 & 29 & & 68 & 11 \\
\hline Mean & 13.2 & 2.5 & & 13.2 & 4.8 & & 11.3 & 1.8 \\
\hline$S D$ & 4.6 & 2.0 & & 8.7 & 6.1 & & 7.1 & 3.1 \\
\hline
\end{tabular}

*Participant's code number 


\section{Path and manner}

All identified gestures were coded for whether they encoded only path $(P)$, only manner (M) or conflated path and manner (PM) when both elements are present in one gesture. This coding was based on the structural properties of the gestures alone and was done with sound turned off, so as to avoid circularity when gesture information was compared to speech information. Gestures were coded as expressing path $(P)$ when they encoded an identifiable single 'spatial excursion' (Kendon, 2004) laterally, vertically or sagittally from the speaker's body. Gestures were coded as expressing manner $(M)$ if they encoded (a) complex paths, for instance repeated up and down movements to indicate jumping, (b) wriggly movement of fingers, (c) grasping hand shapes, (d) movements by feet or legs like walking or cycling, or whole body movements.

\section{Co-expressivity}

Gesture and speech were also coded for co-expressivity. To explore the overlap between meaning conveyed in speech and gesture, we examined the speech that co-occurred temporally with gesture strokes. Notice that this is a narrower definition of 'overlap' than is often applied. Meaning in speech and gesture is sometimes said to overlap when similar meaning is expressed in speech anywhere in the utterance or the clause during which the gesture occurs. However, in a perspective of coexpressivity, the narrower focus seems more appropriate. Moreover, since an additional issue is whether gestures are recruited to compensate for expressive difficulties in speech, it is crucial to consider co-occurring speech to determine possible encoding problems. Cases of Total overlap were instances where gestures and co-occurring speech encoded identical information (i.e., speechP-gestureP, speechM-gestureM, and speechPM-gesturePM). When there was non-redundancy - i.e., when gestures and speech expressed different information - gestures could add information not in speech, Gesture supplementing (i.e., speechP-gestureM, speechP-gesturePM, speechM-gestureP, and speechM-gesturePM), or gestures could be underspecified, expressing only part of the information in speech, Gestures underspecified (i.e., speechPM-gestureP, and speechPM-gestureM).

\section{Viewpoint}

Finally, gestures were coded for viewpoint using McNeill's (1992) distinction between character- and observer viewpoint. Character-viewpoint (C-VPT) gestures incorporate the speaker's body into gesture space such that the protagonist's body parts are mapped onto the speaker's body. These are cases of enactment. In contrast, in observer-viewpoint gestures (O-VPT) the speaker's hands typically represent the protagonist as a whole as seen from the outside.

\section{Interrater reliability}

Interrater reliability of the gesture coding was established by having a second coder judge the data. The interrater agreement on gesture identification was $97 \%$, on content coding (path, manner) 96\%, on co-expressivity coding 100\%, and on viewpoint coding (character- vs. observer-viewpoint) $97 \%$. In cases of discrepancy, the judgement of the second coder was retained. 


\section{RESULTS}

\section{Speech}

Table 3 summarizes the semantic information that was expressed in verbal responses, including propositions which were coded as target responses (whether in singlesentence or multi-sentence responses), as well as other propositions not selected for analysis, in the case of multi-sentence responses. Figure 1 shows the distribution of target responses that expressed path alone (P), manner alone (M) or both (PM) as a function of age for each event type. ${ }^{8}$

Propositions coded as target responses

Upward motion (Fig. 1a) elicited two response types: P-responses (59\% overall) containing a path verb and no manner information; PM-responses (39\%) containing

Table 3 Number and percentage of semantic elements expressed in propositions coded as target responses vs. other propositions

\begin{tabular}{|c|c|c|c|c|c|c|c|c|}
\hline \multirow[t]{2}{*}{ Propositions } & \multicolumn{4}{|c|}{ Main items } & \multicolumn{4}{|c|}{ Control items } \\
\hline & $4 y r s$ & 6 yrs & Adults & Total & $4 y r s$ & 6 yrs & Adults & Total \\
\hline \multicolumn{9}{|l|}{ Target } \\
\hline$P$ & $\begin{array}{l}69 \\
(64 \%)\end{array}$ & $\begin{array}{l}64 \\
(59 \%)\end{array}$ & $\begin{array}{l}58 \\
(54 \%)\end{array}$ & $\begin{array}{l}191 \\
(59 \%)\end{array}$ & $\begin{array}{l}1 \\
(1 \%)\end{array}$ & $\begin{array}{c}14 \\
(19 \%)\end{array}$ & $\begin{array}{l}3 \\
(4 \%)\end{array}$ & $\begin{array}{l}18 \\
(8 \%)\end{array}$ \\
\hline M & $\begin{array}{l}24 \\
(22 \%)\end{array}$ & $\begin{array}{l}12 \\
(11 \%)\end{array}$ & $\begin{array}{l}1 \\
(1 \%)\end{array}$ & $\begin{array}{l}37 \\
(11 \%)\end{array}$ & $\begin{array}{l}65 \\
(90 \%)\end{array}$ & $\begin{array}{l}38 \\
(53 \%)\end{array}$ & $\begin{array}{l}44 \\
(61 \%)\end{array}$ & $\begin{array}{l}147 \\
(68 \%)\end{array}$ \\
\hline PM & $\begin{array}{l}8 \\
(7 \%)\end{array}$ & $\begin{array}{l}29 \\
(27 \%)\end{array}$ & $\begin{array}{l}49 \\
(45 \%)\end{array}$ & $\begin{array}{l}86 \\
(27 \%)\end{array}$ & 0 & $\begin{array}{l}16 \\
(22 \%)\end{array}$ & $\begin{array}{l}25 \\
(35 \%)\end{array}$ & $\begin{array}{l}41 \\
(19 \%)\end{array}$ \\
\hline Residual & $\begin{array}{l}7 \\
(6 \%)\end{array}$ & $\begin{array}{l}3 \\
(3 \%)\end{array}$ & $\begin{array}{l}0 \\
(0 \%)\end{array}$ & $\begin{array}{l}10 \\
(3 \%)\end{array}$ & $\begin{array}{l}6 \\
(8 \%)\end{array}$ & $\begin{array}{l}4 \\
(6 \%)\end{array}$ & $\begin{array}{l}0 \\
(0 \%)\end{array}$ & $\begin{array}{l}10 \\
(5 \%)\end{array}$ \\
\hline Total & 108 & 108 & 108 & 324 & 72 & 72 & 72 & 216 \\
\hline \multicolumn{9}{|l|}{ Other } \\
\hline$P$ & 5 & 9 & 14 & $\begin{array}{l}28 \\
(34 \%)\end{array}$ & 1 & 5 & 12 & $\begin{array}{l}18 \\
(43 \%)\end{array}$ \\
\hline M & 9 & 10 & 20 & $\begin{array}{l}39 \\
(47 \%)\end{array}$ & 2 & 3 & 12 & $\begin{array}{l}17 \\
(40 \%)\end{array}$ \\
\hline PM & 2 & 2 & 9 & $\begin{array}{c}13 \\
(16 \%)\end{array}$ & 0 & 0 & 5 & $\begin{array}{c}5 \\
(12 \%)\end{array}$ \\
\hline Residual & 1 & 2 & 0 & $\begin{array}{l}3 \\
(4 \%)\end{array}$ & 0 & 2 & 0 & $\begin{array}{l}2 \\
(5 \%)\end{array}$ \\
\hline Total & 17 & 23 & 43 & 83 & 3 & 10 & 29 & 42 \\
\hline
\end{tabular}


either a path verb with peripheral manner (e.g., monter en courant 'to ascend by running') or a main verb conflating manner and path (in particular grimper 'to climb up'; see Note 1). Downward motion (Fig. 1b) predominantly elicited P-responses $(82 \%)$ with a main path verb ([re]descendre 'descend [again]') and no manner. Crossing events (Fig. 1c) elicited three response types: P-responses (35\%) with a path-verb and no manner (traverser 'to cross' or passer 'to pass'); M-responses (29\%) with a manner verb and no path (e.g., nager dans la rivière 'to swim in the river'); and PM-responses (35\%) containing either a main path verb with peripheral manner (e.g., traverser en courant 'to cross by running') or a main manner verb with peripheral path (e.g., nager jusqu'à l'autre côté 'to swim to the other side'). Control items (Fig. 1d) mostly elicited M-responses (68\%), but also some PMresponses (19\%), and they typically consisted of a manner verb with or without

(a) 100
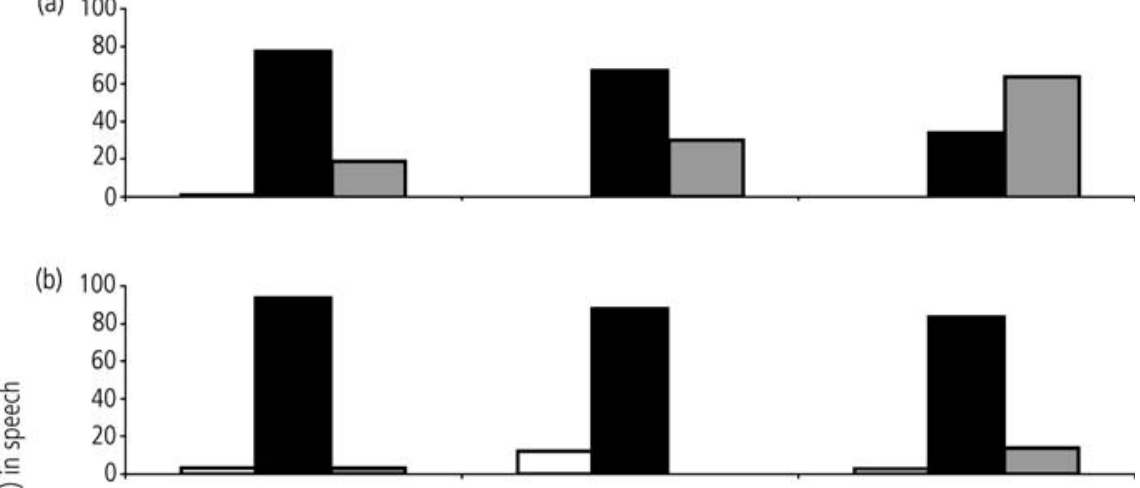

(c) 100

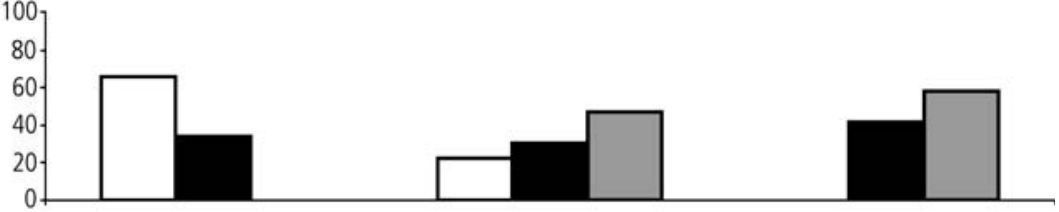

(d)

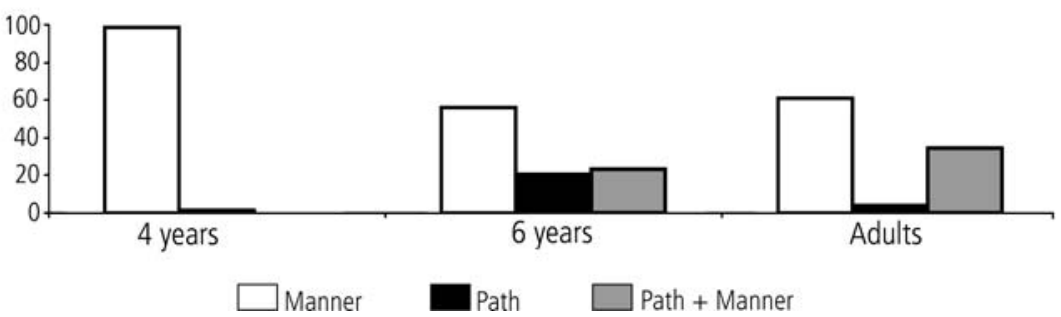

Figure 1 Expression of path and manner in speech (\%) as a function of age for each event type (target responses only): (a) up; (b) down; (c) across; (d) control 
peripheral path information (e.g., marcher 'to walk', marcher de droite à gauche de l'écran 'to walk from right to left of the screen').

Table 4 shows the forms that were produced as main verbs across ages and event types, with particular attention to path verbs (all manner verbs grouped together). Overall, the following uses are predominant: monter ('to ascend', 60\%) and grimper ('to climb up', 33\%) with upward motion; descendre ('to descend', 92\%) with downward motion; traverser ('to cross', 57\%) and manner verbs (36\%) with crossing events. Changes with age concern the following: upward motion shows a decrease of the path verb monter (children $79 \%$ and $69 \%$, adults 33\%) and an increase of verbs that lexicalize path and manner (especially grimper, but also escalader 'to climb up', see Note 1; children $21 \%$ and $31 \%$, adults $53 \%$ ); crossing events show a decrease of manner verbs (4 years $66 \%$, 6 years $31 \%$, adults $14 \%$ ) and an increase of traverser (4 years $23 \%, 6$ years $64 \%$, adults $81 \%$ ).

An ANOVA tested the effects of event type (up, down, across, control) and of age (4 years, 6 years, adults) on the likelihood of responses expressing path alone

Table 4 Number and percentage of main verbs used to denote motion events in the main series by age and event type

\begin{tabular}{lcccc}
\hline Verbs used & 4 years & 6 years & Adults & Total \\
\hline UP & & & & \\
monter 'to ascend & & $25(69 \%)$ & $12(33 \%)$ & $64(60 \%)$ \\
grimper 'to climb up' & $7(21 \%)$ & $11(31 \%)$ & $17(47 \%)$ & $35(33 \%)$ \\
escalader 'to climb up' & 0 & 0 & $6(17 \%)$ & $6(6 \%)$ \\
arriver 'to arrive' & 0 & 0 & $1(3 \%)$ & $1(1 \%)$ \\
Total produced & 34 & 36 & 36 & 106 \\
& & & & \\
DOWN & $31(97 \%)$ & $29(85 \%)$ & $34(94 \%)$ & $94(92 \%)$ \\
descendre 'to descend' & 0 & $1(3 \%)$ & 0 & $1(1 \%)$ \\
aller 'to go' & $1(3 \%)$ & $4(12 \%)$ & $2(6 \%)$ & $7(7 \%)$ \\
manner verbs & 32 & 34 & 36 & 102 \\
Total produced & & & \\
ACROSS & $8(23 \%)$ & $23(64 \%)$ & $29(81 \%)$ & $60(56 \%)$ \\
traverser 'to cross' & $2(6 \%)$ & $2(6 \%)$ & $2(6 \%)$ & $6(6 \%)$ \\
passer 'to pass' & $2(6 \%)$ & 0 & 0 & $2(2 \%)$ \\
avancer 'to go forward' & $23(66 \%)$ & $11(31 \%)$ & $5(14 \%)$ & $39(36 \%)$ \\
manner verbs & 35 & 36 & 36 & 107 \\
Total produced & & & \\
\hline
\end{tabular}

* Uses of monter and descendre include slight variants (remonter/redescendre 'to ascend/descend again'). Some uses of traverser (7 occurrences, of which 2 were produced by 6 -year-olds and 5 by adults) occurred as subordinate verbs in complex sentences with a main manner verb (e.g. courir en traversant 'to run while crossing', nager pour traverser 'to swim in order to cross') 
(P-responses $=1)$. The results show an effect of event type $(F(3,45)=23.13$, $p<0.0001$ ), but no significant effect of age, nor any interaction between these factors. All contrasts among event types were significant, showing that the frequencies of P-responses were ordered as follows: down $>$ up $>$ across $>$ control (down $>$ control, $F(1,15)=117.43, p=0.0000 ;$ up $>$ control, $F(1,15)=27.33$, $p=0.0001$; across $>$ control, $F(1,15)=20.36, p=0.0004$; down $>$ up, $F(1,15)=$ 4.86, $p=0.0416$; down $>$ across, $F(1,15)=32.11, p=0.0000 ; \quad$ up $>$ across, $F(1,15)=3.44, p=0.0804)$. Further event contrasts within each age group showed that at all ages P-responses were more frequent with downward motion than with crossing events (4 years, $F(1,5)=7.10, p=0.0442 ; 6$ years, $F(1,5)=16.87$, $p=0.0098$; adults, $F(1,5)=13.89, p=0.0141$ ) or control items (4 years, $F(1,5)=$ $116.81, p=0.0003$; 6 years, $F(1,5)=20.86, p=0.0066$; adults, $F(1,5)=34.06$, $p=0.0026)$. P-responses were also more frequent with crossing events than with control items, but only among adults $(F(1,5)=17.11, p=0.0095)$, and they were more frequent with upward motion than with control items, but only among children (4 years, $F(1,5)=22.33, p=0.0058 ; 6$ years, $F(1,5)=9.32, p=0.0283$ ). No other contrasts were significant (across vs. up, up vs. down).

Although age had no overall significant effect on P-responses, a closer look at Fig. 1 shows that responses changed in two ways with increasing age. First, PM-responses clearly increased from 4 years to adults with upward motion (from $21 \%$ to $64 \%$ ) and crossing events (from none to $58 \%$ ), as well as to a lesser extent with control items (from none to 35\%) and downward motion (from 3\% to $14 \%)$. This change is mostly due to an increase in subordinated manner verbs (used by adults and to a lesser extent by 6-year-olds). As a result, a substantial decrease in P-responses can be observed with upward motion between children (79\% and $67 \%$ ) and adults (36\%). Second, M-responses decreased with age, particularly with crossing events (from $66 \%$ to no occurrence) and to a lesser extent with control items (from $98 \%$ to $61 \%$ ). However, the 6-year-olds showed an unexpected pattern. On the one hand, they produced the most M-responses with downward motion (12\%), although manner was generally rare with these events (3\% at other ages). On the other hand, they produced a noticeable number of P-responses (21\%) with control items, with which path was generally rare $(2 \%$ and $4 \%$ at other ages).

\section{Other propositions in multi-sentence responses}

In comparison with the results concerning target propositions, other propositions produced by participants in multi-sentence responses (not included in Fig. 1) show more M-responses with main items at all ages (overall 49\%). Although these propositions are clearly less frequent than target propositions at all ages, they do show a clear concern for manner (ambiguously bearing on target vs. other events), which is in fact comparable to the one observed with control items (see Fig. 1 and Table 3). A closer look reveals that, regardless of age, the majority of all multi-sentence responses occurred with crossing events (overall 65\%) in comparison with upward and downward motion (25\% and 10\%), and that most of them focused on manner alone (65\% M-responses), while fewer focused on path alone (25\% P) or on path and manner jointly (10\% PM). 


\section{Summary}

The semantics of French speakers' speech about motion events shows four main results. First, when events involved equally relevant path and manner information (main items), French speakers either strongly focused their speech on path information in path-only responses, especially with downward motion at all ages, or combined path and manner, especially with upward motion at all ages and with crossing events at adult age. Second, path-manner responses increased with age as a result of an increasing use of complex constructions (subordinated manner verbs). Third, responses focusing on manner alone were more frequent with crossing events than with other main items in the children's groups, whereas they were the predominant response type with control items in all age groups. Finally, some responses consisted of multiple sentences that were successively strung together in discourse, showing some concern for expressing manner in utterances surrounding path-oriented target responses.

\section{Gestures}

Gesture data are different in nature from speech data in that not every participant necessarily gestures for each item, each spoken description or even each event type (see Table 2). There is thus considerable variability, which, in combination with the small number of subjects, means that the gesture data do not lend themselves to inferential statistical analyses equivalent to those of speech. Nevertheless, to highlight the parallelism between speech and gesture, we present the gesture data quantitatively, but refrain from statistical treatment. As for speech, the first analysis centres on what information tends to be encoded in gestures by French speakers. The second analysis focuses on the degree of co-expressivity or overlap between gestures and speech also as a function of age.

\section{The encoding of path and manner in iconic gestures}

Figure 2 summarizes the overall proportions of gestures that encoded path $(\mathrm{P})$, manner $(\mathrm{M})$ or both path and manner conflated (PM) in gestures as a function of age (4 years, 6 years, adults) and event type (up, down, across, control).

In all age groups, $\mathrm{P}$ gestures overwhelmingly dominated the main event types describing upward/downward motion and crossing (Figs 2a-2c). Downward motion in particular generated $\mathrm{P}$ gestures (Fig. 2b). All age groups also produced a much smaller proportion of $\mathrm{M}$ gestures for these events, especially for upward motion (Fig. 2a) and crossing events (Fig. 2c). Strikingly, children also produced PM gestures conflating path and manner for all three main event types, whereas adults never did. Looking further at the differences between age groups, such conflated PM gestures became less frequent with age for all event types, but the reduction was greatest for upward motion (Fig. 2a) where 4-year-olds produced a fair amount of PM gestures (33\% or 13/39), in comparison with 6-year-olds ( $11 \%$ or $3 / 28)$ and adults (0 occurrences). There were also fewer $\mathrm{M}$ gestures with age for all events. Although the crossing items generated $M$ gestures in all groups, they were more frequent in both child groups ( $26 \%$ or $6 / 23$ at age $4 ; 27 \%$ or $9 / 33$ at age 6$)$ than in the adults (14\% or $5 / 37)$. Similarly, all speakers produced $\mathrm{M}$ gestures for upward motion (Fig. 2a) but the 4-year-olds produced 
(a) 100
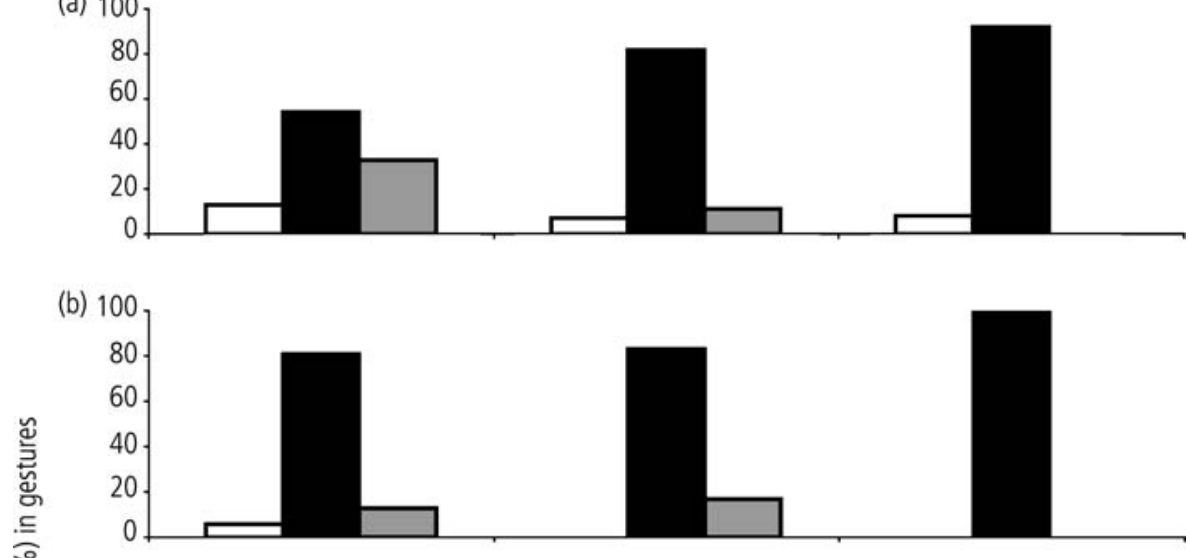

(c) 100

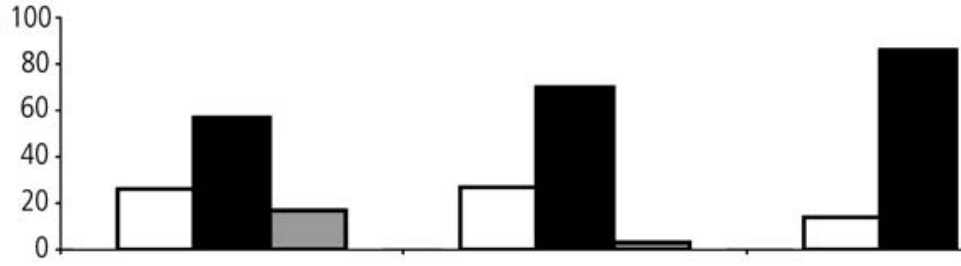

(d) 100

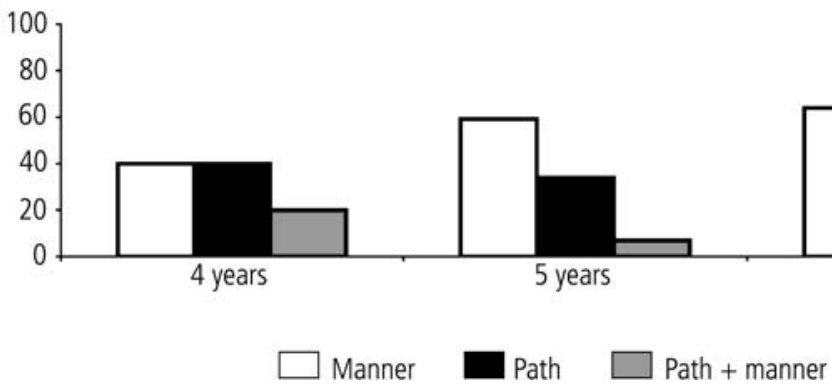

Figure 2 Expression of path and manner in gestures (\%) as a function of age for each event type (target responses only): (a) up; (b) down; (c) across; (d) control

more $(13 \%$ or $5 / 39)$ than the others ( $7 \%$ or $2 / 28$ at age $6 ; 8 \%$ or $1 / 12$ in adults). Finally, only 4-year-olds produced $\mathrm{M}$ gestures for downward motion (6\% or $1 / 16)$.

The control items (Fig 2d), which were designed to focus specifically on manner, generated a somewhat different pattern. Adults and 6-year-olds mainly produced M gestures (59\% or $17 / 29$ at age 6 and $64 \%$ or $7 / 11$ in adults). The next most frequent type was $\mathrm{P}$ gestures (34\% or $10 / 29$ at age $6 ; 27 \%$ or $3 / 11$ in adults). The 4 -year-olds displayed an equal preference for $P$ and $M$ gestures ( $40 \%$ or $6 / 15)$. For these items all groups also produced conflated PM gestures, even the adults, but again, the 4-year-olds outperformed both other groups (20\% or $3 / 15$ at age $4 ; 7 \%$ or $2 / 29$ at age $6 ; 9 \%$ or $1 / 11$ in adults). 
To summarize thus far, with items that involve equally relevant path and manner information (main items), French speakers mainly gestured about path, in particular for downward motion. They gestured to a much lesser extent about manner, and mainly when they were driven to focus their speech specifically on manner (control items). Second, French adults clearly favoured separate expressions of path and manner in gesture over conflated ones. These preferences are in accordance with the expectations for speakers of a verb-framed language. Third, children overall appeared well attuned to the adult patterns and also mainly gestured about path separately. However, although the focus on path could be observed at all ages, children gestured more than adults about manner and, critically, about path and manner conflated, especially for upward motion. Children tended to produce fewer such conflated path-manner gestures with age. Overall, the pattern in gesture production for the main items mirrored that found in speech with the striking exception of conflated expressions. The decrease in production of PM gestures with age contrasted with the increase of PM expressions in speech with age.

\section{Speech-gesture co-expressivity}

The second analysis investigates to what extent gestures and speech are co-expressive, i.e., overlap in meaning, and whether there is any evidence that gestures are recruited to convey other meaning than speech, especially by children. Recall that overlap between speech and gesture was explored by examining speech temporally aligned with gesture strokes. This analysis focuses on expressions of path (P), manner ( $\mathrm{M})$ and path-manner (PM), excluding spoken expressions encoding neither path nor manner (coded as Z). ${ }^{9}$ Figure 3 summarizes the proportions of expressions

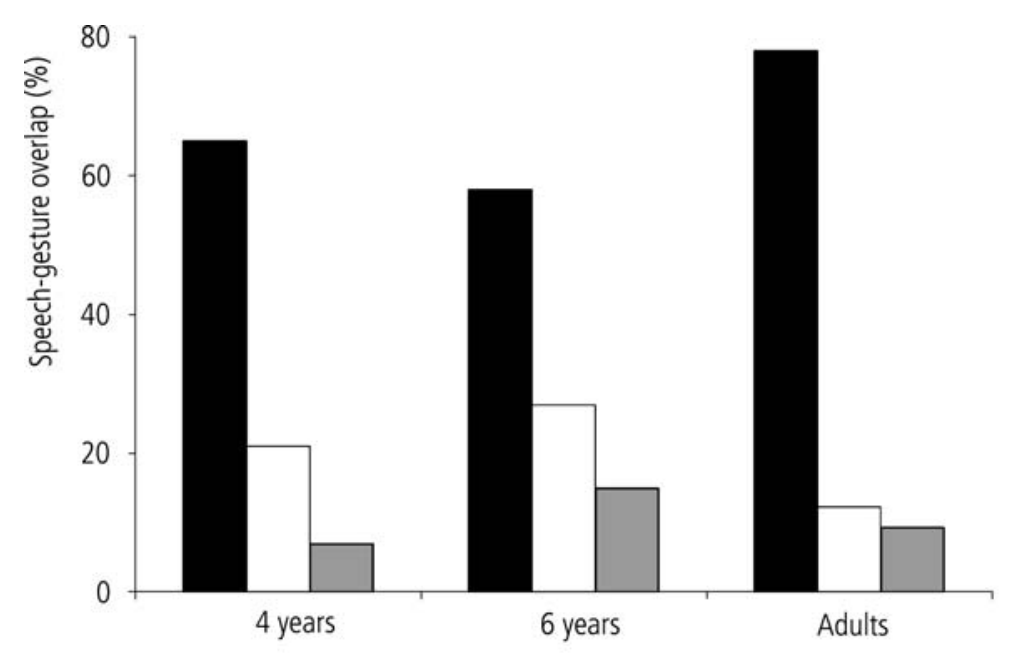

Total overlap $\quad \square$ Gestures supplement $\quad \square$ Gestures underspecified

Figure 3 Speech-gesture overlap (\%) on main items as a function of age 
displaying Total overlap, Gestures supplement and Gestures underspecified for main items in each age group.

For all groups, cases of total overlap dominate the speech-gesture production ( $65 \%$ or $48 / 74$ at age $4 ; 58 \%$ or $41 / 71$ at age $6 ; 78 \%$ or $51 / 65$ in adults). Speech and gestures were thus predominantly co-expressive. Children looked remarkably similar to adults and to one another. The alignment in cases of overlap was largely carried by $\mathrm{P}$ gestures in all groups co-occurring with path verbs such as monter 'ascend', descendre 'descend' and traverser 'cross', and with a variety of peripheral path expressions such as de droite à gauche 'from right to left', par la branche 'via the branch', par là, jusqu'à l'arbre 'through there to the tree', le long de la table 'along the table'. Examples are given in (17)-(19).

(17) il est monté par la branche

(0407, XSIN)

'he ascended via the branch'

(18) il est redescendu là

(0618, XORS)

'he descended there'

(19) traverse cette riv(ière)

(AD09, XGLI)

'crosses this ri(ver)'

M gestures typically aligned with manner verbs such as courir 'run', nager 'swim', sauter 'jump', but also with peripheral or other manner expressions such as à quatre pattes 'on all fours', faire du crawl 'do the crawl', as shown in (20)-(22).
(20) il a couru dans la neige
(0422, XGLI)
'he ran in the snow'
(21) il a marché à quatre pattes
(0618, XBEB)
'he walked on all fours'
(22) nage un peu
(AD07, XNAG)
'swims a little'

Finally, PM gestures, which occurred only in the children's groups, did co-occur with the matching PM verb grimper 'climb up', as seen in (23), but only in the 4-year-olds.

\section{(a)près il a grim(pé là)}

'(a)fter he climb(ed there)'

(0414, XECU)

Despite the overall quantitative similarities between the groups in total overlap, some interesting qualitative differences could be observed in the cases of non-redundancy. Children were somewhat more inclined to add or supplement information in gesture ( $28 \%$ or $21 / 74$ at age $4 ; 27 \%$ or $19 / 71$ at age 6 ) than were adults $(12 \%$ or $8 / 65)$. In addition, 6-year-olds were more likely to produce under-specifying gestures (15\% or $11 / 71)$ than 4 -year-olds $(7 \%$ or $5 / 74)$ and adults $(9 \%$ or $6 / 65)$. The nonredundancy in adults was chiefly caused by the fact that both manner verbs like glisser 'slide', sauter 'jump', nager 'swim', and path-manner expressions like grimper 'climb up' (see Note 1), were all mostly accompanied by P gestures. Critically, grimper 'climb 
up' was never accompanied by conflated PM gestures. French adults thus tended to add gestural path to spoken manner or to target only path in path-manner expressions. They seemed to 'foreground' the path component or, alternatively, to 'downplay' the manner component. Their M gestures, mainly generated by the control items, always aligned with spoken expressions of manner.

The most common type of non-redundancy in 4-year-olds were cases where PM gestures were produced with path verbs like monter/descendre 'ascend/descend', traverser 'cross', adding a manner component where it was absent in speech. The 4-year-olds also produced $M$ gestures with path-manner verbs like grimper 'climb up', thus 'fore-grounding' manner in these expressions. The 4-year-olds thus seemed inclined to provide additional manner in gesture either conflated with path when absent in speech (spoken path) or in pure form when it was partially present in speech (spoken path-manner). The 6-year-olds were between adults and younger children. Like adults, they aligned $\mathrm{P}$ gestures with spoken manner and path-manner expressions. They also added path in conflated PM gestures to spoken manner, going even further than adults, adding path where it was absent from speech. But like the 4-year-olds, they also added gestural manner when absent from speech, and produced conflated PM as well as $\mathrm{M}$ gestures with path verbs like monter/ descendre 'ascend/descend'. The 6-year-olds seemed to add both path and manner gesturally when these components were absent from speech.

The focus on different components across the age groups was apparent in the Gestures supplement category where children and adults preferentially either added gestural path or manner. Adults always added gestural path information (14/14 instances). The 4-year-olds added path much less often than manner (8/26 vs. 18/26) and 6-year-olds added both roughly equally often (path 17/30 and manner 13/30).

To summarize, children like adults were overwhelmingly co-expressive in speech and gesture. However, children and adults differed qualitatively in what types of information they encoded gesturally when the modalities were not co-expressive. While adults' gestures always added path information, children added both path and manner information in gesture when it was absent from co-occurring speech, with the youngest children mainly targeting manner and the older children homing in on path, in an adult-like fashion.

\section{Viewpoints}

One reason why children appear to gesture more than adults about manner, either as $\mathrm{M}$ or as conflated PM gestures, could be a greater tendency to produce gestures typical of a character-viewpoint, enacting events with the entire body. This would bias children's gestures towards manner regardless of the typological properties of the language they are acquiring. Table 5 shows the viewpoints expressed in the gestures produced in the main series, distinguishing character-viewpoint (C-VPT) from observer-viewpoint (O-VPT), as well as whether the gestures encode P, M and PM.

There was an overall preference for O-VPT in all groups, but children were somewhat more likely than adults to produce C-VPT gestures (18\% or $14 / 79$ at age 4; $13 \%$ or $10 / 79$ at age $6 ; 7 \%$ or $5 / 68$ in adults). Further, in all age groups, M was predominantly encoded as C-VPT. Interestingly, however, children's conflated PM 
Table 5 Number of gestures expressing path (P), manner (M) or path-manner (PM) as a function of character viewpoint (C-VPT) vs. observer viewpoint (O-VPT) in the main series

\begin{tabular}{|c|c|c|c|c|c|c|c|c|c|c|c|c|}
\hline & \multicolumn{4}{|c|}{4 years } & \multicolumn{4}{|c|}{6 years } & \multicolumn{4}{|c|}{ Adults } \\
\hline & $P$ & $M$ & $P M$ & Tot. & $P$ & $M$ & $P M$ & Tot. & $P$ & $M$ & $P M$ & Tot. \\
\hline C-VPT & 0 & 10 & 4 & 14 & 0 & 9 & 1 & 10 & 0 & 5 & 0 & 5 \\
\hline O-VPT & 47 & 2 & 16 & 65 & 61 & 2 & 6 & 69 & 62 & 1 & 0 & 63 \\
\hline Total & 47 & 12 & 20 & 79 & 61 & 11 & 7 & 79 & 62 & 6 & 0 & 68 \\
\hline
\end{tabular}

gestures were predominantly expressed as O-VPT. That is, children mapped the protagonists onto their hands in the adult-like fashion, rather than enacting the event, mapping the protagonists onto their whole bodies. This pattern makes it unlikely that the overall tendency for children's non-redundant meaning to be manneroriented was motivated by an overall preference for C-VPT.

\section{Comme ça}

Even if children's gestures overall were co-expressive with speech, their PM conflated gestures could be instances of gestural compensation for that which they could not achieve in speech. Cases where gestures accompany deictic expressions such as comme ça 'like that', which directly refer to the gesture performed, can shed some light on this. Adults in this sample never produced such speech-gesture combinations for items in the main series whereas both 4- and 6-year-olds did. Children mainly accompanied these deictic expressions with conflated PM gestures (6 occurrences at age 4, and 5 at age 6). Such combinations could arguably be seen as an indication of difficulty of expression, and gestures could be expected to be mimetic enactments of motion. However, note that, as we have just seen, conflated PM gestures tended not to be enactments but rather to be performed in O-VPT. Moreover, even the youngest children first produced an adequate verb to describe the action while performing the gesture, and only then added comme ça, as seen in (24) and (25). Thus, the gesture stroke had already started during the production of the verb and then continued during comme ça.

(24) grimpé comme ça

(0412, XCHE)

'climbed up like that'

(25) elle a elle a traversé comme ça

'she she crossed like that'

(0422, XPAT)

These qualitative gesture data confirm the clear findings in the spoken responses (see p.219), showing that control items predominantly elicited reference to manner in speech, in contrast to main items which chiefly elicited reference to path. Both pieces of evidence (speech and gestures) show that children have no difficulties in 
finding the adequate spoken label. Conversely, the fact that children know the manner verbs makes it unlikely that their conflated PM gestures are compensatory in nature. Instead, children's use of deictic expressions like comme ça in speech, referring directly to the PM gestures, seems to reflect a need to further elaborate and embellish the description gesturally.

\section{DISCUSSION AND CONCLUSIONS}

This study investigated how French adults and children (aged 4 and 6 years) encode information about path and manner in speech and accompanying iconic gestures, and the extent to which gestures are co-expressive with speech. The findings can be summarized around three main points.

First, as predicted for speech, when French speakers describe motion events in which path and manner are equally relevant, children as well as adults focus their utterances mostly on the path of motion, but less frequently and less systematically on manner. Some variations also occur as a function of event types and of age. Descriptions of downward motion draw the most frequent path expressions at all ages. Although path is also expressed with upward motion and crossing, expressions simultaneously encoding path and manner increase with age with these events. Finally, French speakers sometimes also encode manner alone in speech, in particular when talking about crossing, or when describing events in which manner is the only salient component (control items). These results are quite similar to the ones previously reported for French, based on a similar experimental procedure (Hickmann, 2006; see Note 6) with the possible exception of the 6-year-olds, who showed a somewhat unexpected behaviour in the present study: a slightly greater focus on spoken manner with downward motion and on path with control items, in comparison with other age groups. This behaviour was not accompanied by a parallel unusual behaviour in gestures and perhaps reflects a transitional stage during language acquisition, a hypothesis that requires further data from older children.

Second, French children and adults overwhelmingly gesture about path alone when path and manner are equally relevant, as predicted, and especially for downward motion. However, when talking about crossing or manner-salient events, they also encode manner alone in gesture. Already by age 4 , children overall pattern like adults, with one exception. Adults have a very strong preference for encoding path and manner separately in gestures as opposed to conflating the two. Children, in contrast, also produce some conflated path-manner gestures, but these become less frequent with age.

Third, speech and gestures are predominantly co-expressive at all ages such that gesture strokes align with spoken elements which encode the same semantic information. Children do not appear to differ from adults in this respect, contrary to some of our expectations. However, in cases of non-redundancy across the modalities, children and adults do differ in that children are inclined to express additional manner in gesture, often as conflated path and manner, sometimes in conjunction with expressions like comme ça, whereas adults tend to express additional path. Moreover, although children's non-redundant meanings tend to be manner-oriented, 
as expected, they are not all encoded in character-viewpoint. Children and adults alike predominantly express gestural meaning from an observer-viewpoint. However, all age groups also tend to express manner alone in character-viewpoint, whereas conflated path and manner is generally encoded in observer-viewpoint, regardless of co-expressivity. It therefore seems unlikely that children's tendency towards additional manner should be driven by a general preference for character-viewpoint.

The bulk of the results concerning the semantics of speech about motion follow from the properties of French. As a verb-framed language, French invites speakers to lexicalize path in main verbs, thereby requiring manner to be expressed at the periphery of the verbal network, either by simple means (adverbials such as à quatre pattes 'on all fours') or by more complex ones (subordinated clauses such as en courant 'by running'). In this respect, the fact that responses encoding both path and manner were more frequent from 4 years on with upward motion follows from the existence of a common verb simultaneously lexicalizing these two types of information (namely grimper 'to climb up'; see Note 1), whereas such verbs are less commonly available for the other motion events examined in the present study (downward, crossing). Indeed, a large proportion of PM-responses with these events consisted of using this particular verb. In contrast, PM-responses with crossing events frequently involved some gerunds (e.g., traverser en courant 'to cross by running').

The strong focus on manner with control items was expected, since these items were precisely meant to make manner information maximally salient and path as minimally relevant as possible. The high frequency of M-responses with control items clearly shows that rare uses of manner verbs, particularly in descriptions of upward and downward motion, is not due to the fact that young children do not have access to such manner verbs in their productive lexicon. When speakers expressed path with these items (in P and PM responses), they typically used adverbials or prepositional phrases expressing direction and/or source/goal locations (e.g., courir vers la gauche 'to run towards the left', marcher de droite à gauche 'to walk from right to left', avancer en partant de la gauche de l'écran 'to move forward by leaving from the left of the screen'). Finally, with respect to crossing events, young children's partial focus on manner alone might be related to the fact that the verb traverser ('to cross') is not yet entirely productive in their lexicon. This lexical gap, which was also observed in previous research (Hickmann, 2006), might lead speakers to use a manner verb either alone (nager 'to swim') resulting in an Mresponse (at 4 years), or with peripheral path expressions (nager jusqu'à l'autre bout 'to swim to the other end', courir de droite à gauche 'to run from left to right'), resulting in a PM-response (at 6 years and adult age).

The gesture data suggest a similar focus on path with French adults and children overwhelmingly encoding only path (in observer-viewpoint) in their gestures, and, conversely, showing a relative disinterest in manner unless specifically isolated as the only newsworthy component. French speakers do produce separate manner gestures when talking about crossing events or manner-salient events. Adults crucially only produce such gestures when they also talk about manner simultaneously. This overall focus on path, and the tight co-expressivity in French adults' speech and gesture - in particular the absence of gestures expressing manner unless manner is also present 
in speech - is in seeming opposition to the reported pattern in Spanish, another verb-framed language. Recall that Spanish speakers produce manner gestures even when overt manner is absent from speech (Duncan, 2005; McNeill \& Duncan, 2000), supposedly because gestures offer a convenient expressive means for manner (McNeill, 2000), where no simple spoken encoding option is available. As another verbframed language, French could have displayed a similar pattern. However, French adults only produce manner gestures with spoken manner, and, moreover, they occasionally add path gestures to spoken manner in the main series. There is thus little support for a compensatory view of the production of (manner) gestures in French as a verb-framed language (for a similarly non-compensatory view of the Spanish pattern, see Duncan, 2005). Instead, the French data are more in line with findings suggesting that speakers of Turkish and Japanese, also verb-framed languages, align their path and manner gestures with speech that expresses these components (Brown \& Gullberg, 2008; Kita \& Özyürek, 2003; Özyürek et al., 2005). As such, the findings are compatible with the Interface hypothesis (Kita \& Özyürek, 2003), according to which both imagistic and linguistic influences shape gestures. The strong predominance of linguistic over imagistic influences in the French data is not, per se, in contradiction to the hypothesis. In fact, the Interface hypothesis in its current form does not make different predictions for a compensatory as opposed to a linguistically conceptually driven view of gesture production, nor does it make specific predictions for how strong the influence of each component should be.

Obviously, because our gesture data are only exploratory at this point, the findings must be treated with caution and will require analyses based on a larger set of data for confirmation. However, it is possible that the lack of 'orphan' manner gestures in French relative to Spanish is due to a richer inventory of manner verbs in French with a subsequent attenuated need to convey manner in gesture alone (although, consider Duncan's (2005) observation that spoken Spanish descriptions can be very rich in manner expressions depending on the type of motion depicted). Of course, there may also be pragmatic reasons for why manner was not highlighted in this study for the main items. Finally, methodological differences in data collection, as well as in the operationalization of speech-gesture 'overlaps' may also account for these unexpected differences.

French children overwhelmingly follow the gestural patterns of adults, focusing mainly on path and expressing it in observer-viewpoint. There is little evidence that children in these age groups rely on holistic gestural representations of motion. However, children are somewhat more prone than adults to express manner in gesture, either separately or conflated with path. This is why they appear more likely than adults to add information in gesture absent from speech. A tempting interpretation of this pattern is that they express manner in gesture because they cannot easily encode it in speech. However, as for adults, there are reasons to doubt such a compensatory view. Recall that even when children produce conflated gestures encoding path and manner simultaneously, they often do so while using adequate path and manner expressions in speech, even in conjunction with deictic expressions such as comme ça 'like that'. Moreover, as seen above, data from the control series show that children do not have lexical difficulties as such for the domain of manner. There is thus little support for the notion that French children 
recruit iconic gestures to compensate for linguistic, or at least lexical, difficulties. Whatever verbal difficulties children have, they seem rather to be linked to the need to use complex utterance structures to encode both path and manner in speech, when verbs conflating both types of information (such as grimper) are not available to them or even exist in the adult system, e.g., for downward motion or crossing events (see Hickmann, 2006). These gesture results are in accordance with previous findings concerning adult second language learners (Gullberg, 1998, 1999) as well as children of these age groups. Examining English-French bilingual children, Nicoladis and colleagues (Nicoladis, 2002; Nicoladis \& Genesee, 1996) have shown that, although children may recruit deictic gestures to overcome expressive difficulties in their weaker language, the rate of iconic gestures is higher in their more proficient language. They have suggested that this is because the relationship between iconic gestures and speech is closer than that of other kinds of gestures. The present data support this proposal.

Returning to the question that motivated the study, we may now briefly explore the implications of these findings for our understanding of speakers' conceptual representations. In particular, what might the main results indicate about how motion is or is not conceptualized in French? Perhaps the only clear answer to this question at this point is a 'negative' one, in the sense that the findings inform us about what speakers' representations presumably are not in most circumstances. Thus, the fact that French speakers simultaneously focus their speech and their gestures on path would seem to suggest that they do not conceptualize manner as part of the linguistic representation they are constructing while talking about motion. Alternatively, a weaker version of this hypothesis would be that manner is part of their linguistic representation, but not at its centre, remaining so to speak in a state of 'fuzzy out of reach', unless or until it is called upon for particular discourse needs.

In this respect, the variations that were observed in French speakers' behaviours across event types and modalities may inform us about the nature of their representations, precisely because they show a variable concern for the expression of manner in speech, depending on the nature of the situations to be described. Thus, a major exception to French speakers' predominant focus on path was observed with events that had been constructed precisely in such a way as to make manner the only obvious component to be talked about (the control series, in which speech and gestures about manner were predominant). In these cases, the relative weight of path and manner is reversed: speakers clearly do not 'downplay' manner, but rather place this information at the centre of their representation. Similarly, crossing events differed from other events in the main series in that they elicited more manner in speech as well as in gestures, presumably because of a gap in children's verbal lexicon. Finally, when subjects produced multi-sentence responses, they strung together expressions that described different aspects of motion in distinct and complementary ways across utterances in discourse (especially children). Such responses show some concern for manner, even when speakers are describing events in the main series. Therefore, manner information can be accessed, although its relevance is often 'fuzzy' (ambiguously relevant to several motion events). 
From a developmental point of view, our results also provide suggestions for what children's representations may or may not be. Even the youngest children in this study show an adult-like focus on path in speech and gesture, and overall coexpressivity between speech and gestures. However, the gesture data, and in particular the cases of non-redundancy between speech and gesture, suggest that children also consider manner. As seen above, it seems unlikely that the cases of additional manner, separate or conflated with path, in gesture relative to co-occurring speech are cases of gestural compensation for encoding difficulties in speech. Rather, these gestures may reflect children's attention to what McNeill (2005) calls the 'full complexity' of motion, i.e., the perceptual characteristics that include both path and manner. Recall that he predicts that children will start to follow languagespecific influences on representations around age 3-4 years, which is when they should prefer to express path and manner separately. Under such a view, the French 4-year-olds may be showing residual tendencies towards holistic, perceptually based, encodings of events. An alternative interpretation is to consider the cases of non-redundancy as indications of cognitive development or transitional knowledge (e.g., Goldin-Meadow, 2003). In this perspective, any misalignments between manner in speech and gestures would indicate that children are working on their representations, exploring options for how to weight and encode the semantic components. The increase of conflated manner and path in speech and decrease of conflated manner and path in gestures over age would seem to favour such a view but, again, more data from these age groups and from developmental stages inbetween would be illuminating in this respect.

In conclusion, although this study is exploratory in nature, it points to several directions for future research that might contribute to providing more 'positive' and precise answers concerning the relationship between speech, gestures and conceptual representations in children and adults crosslinguistically. A first obvious point is that more data are necessary concerning French children and adults, especially given the individual variation that characterizes gestures. Analyses in progress, which include more subjects in each age group and more age groups, as well as other event types, will aim at generalizing the results over a larger sample. Furthermore, these analyses also focus on available speech and gesture data elicited from English speakers in the same age groups and in identical experimental conditions. These data will allow us to test directly the effect of language-specific factors. In particular, in order to determine what gestures might index about speakers' representations, we need to have more crosslinguistic evidence concerning their relative overlap with speech across spatial systems that predominantly rely on verbvs. satellite-framing. If adults' and children's gestures overlap with speech, this type of comparative evidence should show a different pattern of gestures in satelliteframed language.

Complementary clause-based analyses will also be essential in providing a precise view of speakers' representations. In this respect, preliminary evidence in the present data concerns two distinct dimensions of response 'architecture', which are revealing in accounting for the relative semantic density of speech about motion (path-and-manner vs. path- or manner-alone) as a function of age and events: as 
we saw, speakers either encoded information within single utterances or distributed it across utterances in discourse (tight vs. loose architecture); they also either relied on subordination or strung together successive utterances (complex vs. simple architecture). Although responses frequently displayed a tight architecture at all ages, complex architecture increased with age. Furthermore, among all event types studied, crossing events elicited the most frequent tight and complex responses. These patterns are presumably related to two of our findings above, particularly the increasing semantic density of speech with age and its greater density with crossing events than with upward/downward motion (focus on path) or control events (focus on manner). From a crosslinguistic point of view, different patterns should emerge in other languages, particularly in satellite-framed languages such as English, where speech architecture should be almost exclusively tight and simple, irrespective of age.

Finally, the analysis of co-expressivity between speech and gestures will similarly be expanded to allow explorations of how structural constraints may influence gestures and co-expressivity. The current analysis of co-expressivity was based on a narrow criterion of temporal overlap between gestural stroke and speech. We would argue that this narrow focus is necessary given that the theoretical claims about the integration of linguistic cognition, speech and gestures are based on the observation of semantic and temporal alignment as one of the defining criteria (e.g., McNeill, 1985). However, the temporal overlap analysis may over-emphasize the importance of the temporal component and/or obscure other important aspects of the relationship, such as the distribution of information over linguistic planning units like clauses (Kita \& Özyürek, 2003; McNeill, 1992), and systematic relationships of alignment between strokes and spoken elements that are seemingly unrelated, such as the Spanish alignment of manner gestures with nominal ground elements in Spanish (Duncan, 2005). Therefore, a complementary analysis should examine co-expressivity across the clause, the utterance or the 'architecture', and compare it with the temporal overlap analysis. Thus, by changing the grain and scope of our analyses, as well as by exploring larger and more varied data bases, we may hope for a more accurate magnifying lens that will tap deeper into the representations of both children and adults, and get us closer to understanding the processes whereby they are constructed.

\section{ACKNOWLEDGEMENTS}

The research reported here was funded by the programmes 'École et Sciences Cognitives' and 'Éspace et Territoires' initiated by the French Ministry of Research and by the Max Planck Institute for Psycholinguistics, respectively. We gratefully acknowledge technical support from the Max Planck Institute for Psycholinguistics and from the Laboratoire Cognition et Comportement (CNRS, Université René Descartes - Paris 5). We wish to express our special thanks to Pierre Taranne and Sylvain Mottet for their help in programming, as well as to Davide Valentini and Arna Van Doorn for their help with gesture coding and establishment of interrater reliability. We are also grateful for the cooperation of the children, parents, teachers and directors (M. Philippart and Mme Stéfani) of the 'Groupe scolaire Gambetta' in 
Vanves. Finally, we thank two anonymous reviewers and the guest editors for helpful comments.

\section{NOTES}

1. Unlike English 'climb', which encodes manner in combination with a variety of path devices (e.g., climb up, down, away, across ...), French grimper 'to climb up' encodes upward motion carried out in a particular manner, namely using limbs and with some effort. It clearly differs from monter 'to go up', which encodes only upwards direction but no manner, even though both verbs can occur in similar constructions (e.g., monter/grimper l'escalier 'to go/climb up the stairs', monter/grimper à l'arbre 'to go/climb up on[at] the tree'). Thus, the two languages present equivalent contrasts between 'go up' vs. 'climb up' (English) and monter vs. grimper (French). Grimper can be combined with other manners (e.g., to indicate effort, as in Dans la dixième étape du Tour de France, les cyclistes ont dû grimper jusqu'à 2000 mètres d'altitude 'In the tenth stage of the Tour de France, the cyclists had to climb up to an altitude of 2000 metres'). However, it cannot be combined with obviously incompatible manners, for example, when agents lack limbs (e.g., Pendant leur migration, les saumons peuvent remonter/*grimper des cours d'eau en sautant/nageant à contre-courant pour pondre leurs oeufs 'During their migration salmon can leap/swim upstream to spawn'). Other French verbs can lexicalize path-manner, but they are more marked and/or used in a higher register (e.g., dévaler l'escalier 'to rush down the stairs') and/or were rarely used in our study, with the exception of escalader 'to climb up', that typically indicates more limb work, e.g., escalader/?grimper la falaise 'to climb up the cliff'; see example (12).

2. The term 'speech-associated gesture' will be used throughout this paper rather than 'co-speech gesture'. The notion of 'co-speech' seems to suggest not only a semantic-pragmatic link between speech and gesture but also (an obligatory) temporal overlap. Although temporal synchrony between gesture and speech is doubtless generally present, full temporal overlap is clearly not always found, and especially not in developmental data where the issue of temporal alignment is an empirical issue in need of further investigation in its own right. For this reason, we prefer the term 'speech-associated' which highlights the tight relationship between speech and gesture but does not assume full temporal overlap.

3. Children only occasionally used traverser in 'frozen' contexts (most typical of the adult input, e.g., en plus il faut pas traverser 'in addition [one] must not cross'; F0404 XBEB).

4. During the pre-testing, one control item (monkey - item 12 in Appendix) elicited more diverse manners than others (walk funny, kind of dancing ...) and was therefore replaced by a new item (kitten).

5. In our previous studies the two series (main vs. control) were presented in counterbalanced order (main-control vs. control-main). Since an order effect was observed, order was held constant in the present study (always main-control).

6. Participant code (first 2 characters age group; next two characters participant number), and item code (X/C experimental vs. control item); final three characters item, e.g., SOU souris 'mouse'.

7. Statistical analyses were based on raw scores (one response per event type). In addition, since multi-sentence responses could include up to 4 or 5 propositions, and since they often involved redundant information, inclusion of all propositions would have inflated some response types (especially $\mathrm{P}$ at all ages and PM in adults). 
8. No distinction is made between the two series of control items (6 items each, see Appendix), since the results are identical across them. Figure 1 excludes responses other than M, P or PM (Z-responses and no response: control 5\%, main 3\%; see Table 3).

9. Although Z-responses may be informative in relation to non-redundant gestures, they were too infrequent to allow further analyses (overall $25 / 665$ or $3.8 \%$ responses; see Table 3 ).

\section{APPENDIX}

\section{Main across-items}

(1) A man runs to a country road, runs across the road, and runs away.

(2) A girl rides to railroad tracks on a bicycle, rides across the tracks, and rides away.

(3) A baby crawls to a street, crawls across the street, and crawls away.

(4) A boy walks to a river, swims across the river, and walks away.

(5) A boy walks to a frozen river, slides across the river on his boots, and walks away.

(6) A girl walks to a frozen lake with skates on, skates across the lake, and walks away.

\section{Main up/down-items}

(7) A squirrel runs to a tree, up to a hole in the tree, in and out of the hole, down, and away.

(8) A caterpillar crawls to a plant and up to a leaf, eats a piece, crawls down and away.

(9) A bear walks to a tree, climbs up to a beehive, takes honey, climbs down, eats the honey, and walks away.

(10) A cat runs to a telephone pole and up to a bird's nest, drops an egg, jumps down, licks the egg, and runs away.

(11) A mouse tiptoes to a table, climbs up a table leg to a piece of cheese, takes the cheese, slides down, and tiptoes away.

(12) A monkey walks to a banana tree, climbs up, takes a banana, slides down backwards, and walks away.

\section{Control items}

(1) man running; (2) girl riding bicycle; (3) baby crawling; (4) boy swimming; (5) boy sliding; (6) girl skating; (7) squirrel running; (8) caterpillar crawling; (9) bear walking; (10) cat running; (11) mouse tiptoeing; (12) kitten running. 


\section{REFERENCES}

Alibali, M. W. \& Goldin-Meadow, S. (1993). Gesture-speech mismatch and mechanisms of learning: What the hands reveal about a child's state of mind. Cognitive Psychology, 25, 468-523.

Allen, S., Özyürek, A., Brown, A., Furman, R. \& Ishizuka, T. (2003). Early speech about manner and path in Turkish and English: Universal or language-specific? In B. Beachley, A. Brown, \& F. Conlin et al. (Eds), Proceedings of the BUCLD 27 (pp. 63-72). Somerville, MA: Cascadilla Press.

Allen, S., Özyürek, A., Kita, S., Brown, A., Furman, R., Ishizuka, T., et al. (2007). Languagespecific and universal influences in children's syntactic packaging of Manner and Path: A comparison of English, Japanese, and Turkish. Cognition, 102(1), 16-48.

Aurnague, M. (1995). Orientation in French spatial expressions: Formal representations and inferences. Journal of Semantics, 12(3), 249-267.

Aurnague, M. (1996). Les noms de localisation interne: tentative de caractérisation sémantique à partir de données du basque et du français. Cahiers de Lexicologie, 69, 159-192.

Aurnague, M., Hickmann, M. \& Vieu, L. (Eds) (2007). The categorization of spatial entities in language and cognition. Amsterdam: Benjamins.

Berman, R. \& Slobin, D. I. (1994). Relating events in narrative: A crosslinguistic developmental study. Hillsdale, NJ: Erlbaum.

Borillo, A. (1998). L'espace et son expression en français. Paris: Ophrys.

Bowerman, M. (1982). Starting to talk worse: Clues to language acquisition from children's late speech errors. In S. Strauss \& R. Stavy (Eds), U-shaped behavioral growth (pp. 101-146). New York: Academic Press.

Bowerman, M. (1996). The origins of children's spatial semantic categories: Cognitive versus linguistic determinants. In J. J. Gumperz \& S. C. Levinson (Eds), Rethinking linguistic relativity (pp. 145-176). Cambridge: Cambridge University Press.

Bowerman, M. (2007). Containment, support, and beyond: Constructing topological spatial categories in first language acquisition. In M. Aurnague, M. Hickmann \& L. Vieu (Eds), The categorization of spatial entities in language and cognition (pp. 177-203). Amsterdam: Benjamins.

Bowerman, M. \& Choi, S. (2001). Shaping meanings for language: Universal and languagespecific in the acquisition of spatial semantic categories. In M. Bowerman \& S. C. Levinson (Eds), Language acquisition and conceptual development (pp. 475-511). Cambridge: Cambridge University Press.

Bowerman, M. \& Choi, S. (2003). Space under construction: Language-specific spatial categorization in first language acquisition. In D. Gentner \& S. Goldin-Meadow (Eds), Language in mind (pp. 387-428). Cambridge, MA: MIT Press.

Brown, A. (2007). Crosslinguistic influence in first and second languages: Convergence in speech and gesture. Unpublished PhD thesis, Boston University, and MPI for Psycholinguistics, Nijmegen.

Brown, A. \& Gullberg, M. (2008). Bidirectional crosslinguistic influence in L1-L2 encoding of Manner in speech and gesture: A study of Japanese speakers of English. Studies in Second Language Acquisition, 30(2), 225-251.

Brugman, H. \& Kita, S. (1995). Impact of digital video technology on transcription: A case of spontaneous gesture transcription. KODIKAS/CODE: Ars Semeiotica, 18, 95-112.

Capirci, O., Contaldo, A., Caselli, M. C. \& Volterra, V. (2005). From action to language through gesture: A longitudinal perspective. Gesture, 5(1-2), 155-177.

Capirci, O., Iverson, J. M., Pizzuto, E. \& Volterra, V. (1996). Gestures and words during the transition to two-word speech. Journal of Child Language, 3, 645-675. 
Choi, S. \& Bowerman, M. (1991). Learning to express motion events in English and Korean: The influence of language-specific lexicalization patterns. Cognition, 41, 83-121.

Church, R. B. \& Goldin-Meadow, S. (1986). The mismatch between gesture and speech as an index of transitional knowledge. Cognition, 23(1), 43-71.

Clark, H. H. (1996). Using language. Cambridge: Cambridge University Press.

De Ruiter, J.-P. (2000). The production of gesture and speech. In D. McNeill (Ed.), Language and gesture (pp. 284-311). Cambridge: Cambridge University Press.

De Ruiter, J.-P. (2007). Postcards from the mind: The relationship between speech, gesture and thought. Gesture, 7(1), 21-38.

Duncan, S. (1996). Grammatical form and 'thinking-for-speaking' in Mandarin Chinese and English: An analysis based on speech-accompanying gesture. Unpublished PhD thesis, University of Chicago.

Duncan, S. (2005). Co-expressivity of speech and gesture: Manner of motion in Spanish, English, and Chinese. In C. Chang, M. J. Houser, Y. Kim, D. Mortensen, M. Park-Doob \& M. Toosarvandani (Eds), Proceedings of the 27th Annual Meeting of the Berkeley Linguistic Society, 2001 (General Session and parasession on Gesture and Language, pp. 353-370). Berkeley, CA: Berkeley Linguistics Society.

Goldin-Meadow, S. (2003). Hearing gesture: How our hands help us think. Cambridge, MA: The Belknap Press.

Goldin-Meadow, S. \& Butcher, C. (2003). Pointing toward two-word speech in young children. In S. Kita (Ed.), Pointing: Where language, culture, and cognition meet (pp. 85-107). Mahwah, NJ: Erlbaum.

Guidetti, M. (2002). The emergence of pragmatics: Forms and functions of conventional gestures in young French children. First Language, 22(3), 265-286.

Guidetti, M. (2005). Yes or no? How young French children combine gestures and speech to agree and refuse. Journal of Child Language, 32(4), 911-924.

Gullberg, M. (1998). Gesture as a communication strategy in second language discourse. A study of learners of French and Swedish. Lund: Lund University Press.

Gullberg, M. (1999). Communication strategies, gestures, and grammar. Acquisition et Interaction en Langue Etrangère, 2, 61-71.

Hickmann, M. (2003). Children's discourse: Person, space and time across languages. Cambridge: Cambridge University Press.

Hickmann, M. (2006). The relativity of motion in first language acquisition. In M. Hickmann \& S. Robert (Ed.), Space across languages: Linguistic systems and cognitive categories (pp. 281-308). Amsterdam: Benjamins.

Hickmann, M. (2007). Static and dynamic location in French: Developmental and crosslinguistic perspectives. In M. Aurnague, M. Hickmann \& L. Vieu (Eds), The categorization of spatial entities in language and cognition (pp. 205-231). Amsterdam: Benjamins.

Hickmann, M. \& Hendriks, H. (2006). Static and dynamic location in French and English. First Language, 26(1), 103-135.

Hickmann, M., Hendriks, H., Champaud, C. (2008). Typological constraints on motion in French child language. In J. Guo, E. Lieven, S. Ervin-Tripp, N. Budwig, S. Özçalışkan \& K. Nakamura (Eds), Crosslinguistic approaches to the psychology of language: Research in the tradition of Dan Isaac Slobin. Hillsdale, NJ: Erlbaum.

Hickmann, M., Taranne, P. \& Bonnet, P. (submitted). Path and manner in French child language. Journal of Child Language.

Jancovic, M., Devoe, S. \& Wiener, M. (1975). Age-related changes in hand and arm movements as nonverbal communication: Some conceptualizations and an empirical exploration. Child Development, 46(4), 922-928. 
Kendon, A. (1980). Gesticulation and speech: Two aspects of the process of utterance. In M. R. Key (Ed.), The relationship of verbal and nonverbal communication (pp. 207-227). The Hague: Mouton.

Kendon, A. (2004). Gesture. Visible action as utterance. Cambridge: Cambridge University Press.

Kita, S. \& Özyürek, A. (2003). What does cross-linguistic variation in semantic coordination of speech and gesture reveal?: Evidence for an interface representation of spatial thinking and speaking. Journal of Memory and Language, 48(1), 16-32.

Kita, S. \& Özyürek, A. (2007). How does spoken language shape iconic gestures? In S. D. Duncan, J. Cassell \& E. T. Levy (Eds), Gesture and the dynamic dimension of language. Essays in honor of David McNeill (pp. 67-74). Amsterdam: Benjamins.

Kita, S., Van Gijn, I. \& Van der Hulst, H. (1998). Movement phases in signs and co-speech gestures, and their transcription by human coders. In I. Wachsmuth \& M. Fröhlich (Eds), Gesture and Sign Language in Human-Computer interaction (pp. 23-35). Berlin: Springer.

Kopecka, A. (2006). The semantic structure of motion verbs in French. Typological perspectives. In M. Hickmann \& S. Robert (Eds), Space in languages. Linguistic systems and cognitive categories (pp. 83-101). Amsterdam: Benjamins.

Levinson, S. C. \& Wilkins, D. P. (Eds) (2006). Grammars of space. Explorations in cognitive diversity. Cambridge: Cambridge University Press.

Mayberry, R. I. \& Nicoladis, E. (2000). Gesture reflects language development: Evidence from bilingual children. Current Directions in Psychological Science, 9(6), 192-196.

McNeill, D. (1985). So you think gestures are nonverbal? Psychological Review, 92(3), 271-295.

McNeill, D. (1992). Hand and mind. What the hands reveal about thought. Chicago: University of Chicago Press.

McNeill, D. (2000). Imagery in motion event descriptions: Gestures as part of thinkingfor-speaking in three languages. In M. L. Juge \& J. L. Moxley (Eds), Proceedings of the 23rd Annual Meeting of the Berkeley Linguistics Society, 1997 (General session and parasession on pragmatics and grammatical structure, pp. 255-267). Berkeley, CA: Berkeley Linguistics Society.

McNeill, D. (2005). Gesture and thought. Chicago: University of Chicago Press.

McNeill, D. \& Duncan, S. D. (2000). Growth points in thinking-for-speaking. In D. McNeill (Ed.), Language and gesture (pp. 141-161). Cambridge: Cambridge University Press.

Nicoladis, E. (2002). Some gestures develop in conjunction with spoken language development and others don't: Evidence from bilingual preschoolers. Journal of Nonverbal Behavior, 26(4), 241-266.

Nicoladis, E. \& Brisard, F. (2002). Encoding motion in gestures and speech: Are there differences in bilingual children's French and English? In E. V. Clark (Ed.), Space in language. Location, motion, path, and manner. The Proceedings of the 31st Stanford Child Language Research Forum (pp. 60-68). Stanford: CSLI Publications.

Nicoladis, E. \& Genesee, F. (1996). Bilingual communication strategies and language dominance. In A. Stringfellow, D. Cahana-Amitay, E. Hughes \& A. Zukowski (Eds), Proceedings of the 20th Annual Boston University Conference on Language Development (pp. 518-527). Somerville, CA: Cascadilla Press.

Nicoladis, E., Mayberry, R. I. \& Genesee, F. (1999). Gesture and early bilingual development. Developmental Psychology, 35(2), 514-526.

Özçalışkan, S. \& Goldin-Meadow, S. (2005). Gesture is at the cutting edge of early language development. Cognition, 96(3), B101-B113.

Özyürek, A., Kita, S., Allen, S. E. M., Furman, R. \& Brown, A. (2005). How does linguistic framing of events influence co-speech gestures? Insights from crosslinguistic variations and similarities. Gesture, 5(1/2), 219-240. 


\title{
VOLUME 28 ISSUE 2
}

Piérart, B. (1978). Genèse et structuration des marqueurs de relations spatiales entre trois et dix ans. Cahiers de I'Institut de Linguistique (Special Issue: 'Structures cognitives et organisation du langage'), 5(1-2), 41-59.

Pine, K. J., Lufkin, N. \& Messer, D. (2004). More gestures than answers: Children learning about balance. Developmental Psychology, 40(6), 1059-1067.

Senghas, A., Kita, S. \& Özyürek, A. (2004). Children creating core properties of language: Evidence from an emerging sign language in Nicaragua. Science, 305(5691), 1779-1782.

Seyfeddinipur, M. (2006). Disfluency: Interrupting speech and gesture. Unpublished PhD thesis, Radboud University, Nijmegen.

Slobin, D. I. (1996). From "thought and language" to "thinking for speaking". In J. J. Gumperz \& S. C. Levinson (Eds), Rethinking linguistic relativity (pp. 70-96). Cambridge: Cambridge University Press.

Slobin, D. I. (2004). The many ways to search for a frog. In S. Strömqvist \& L. Verhoeven (Eds), Relating events in narrative: Typological and contextual perspectives. Hillsdale, NJ: Erlbaum.

Slobin, D. I. (2006). What makes manner of motion salient? Explorations in linguistic typology, discourse, and cognition. In M. Hickmann \& S. Robert (Eds), Space in languages. Linguistic systems and cognitive categories (pp. 59-81). Amsterdam: Benjamins.

Strömqvist, S. \& Verhoeven, L. (Eds) (2004). Relating events in narrative: Typological and contextual perspectives. Hillsdale, NJ: Erlbaum.

Talmy, L. (2000). Toward a cognitive semantics. Cambridge, MA: MIT Press.

Vandeloise, C. (1991). Spatial prepositions: A case study in French. Chicago: University of Chicago Press.

Verjat, I. (1991). Le statut cognitif des marqueurs 'devant' et 'derrière' chez l'enfant français. L'Année Psychologique, 91, 207-230.

Volterra, V., Caselli, M. C., Capirci, O. \& Pizzuto, E. (2005). Gesture and the emergence and development of language. In M. Tomasello \& D. I. Slobin (Eds), Beyond nature-nurture: Essays in honor of Elisabeth Bates (pp. 3-40). Mahwah, NJ: Erlbaum.

\section{ADDRESS FOR CORRESPONDENCE}

\author{
Dr Marianne Gullberg \\ Max Planck Institute for Psycholinguistics, PB 310, \\ 6500 AH Nijmegen, The Netherlands \\ E: marianne.gullberg@mpi.nl
}

